\title{
¿La declaración responsable como nuevo paradigma de control en el ámbito urbanístico?*
}

\author{
Juan Antonio Chinchilla Peinado \\ Profesor Titular de Derecho Administrativo \\ Universidad Autónoma de Madrid
}

\begin{abstract}
RESUMEN
Al socaire de la crisis económica derivada de la covid-19, un amplio número de Comunidades Autónomas han ampliado el número de supuestos que dejan de estar controlados a través de una licencia y que pasan a controlarse mediante la figura de la declaración responsable (o la comunicación). Un análisis horizontal permite apreciar la inexistencia de una regulación acabada. El trabajo pretende aportar elementos a la caja de herramientas del operador jurídico partiendo de la relación jurídico-urbanistica trabada con la declaración responsable o la comunicación.
\end{abstract}

Palabras clave: urbanismo; licencia; declaración responsable; control administrativo.

\begin{abstract}
In the wake of the economic crisis derived from the covid-19, a large number of Autonomous Communities have increased the number of cases that are no longer controlled through a planning peremission and that are now controlled through the figure of the responsible statement (or the communication). A horizontal analysis shows the lack of a complete regulation. The aim of this paper is to contribute elements to the legal operator's toolbox, starting from the public relationship linked to the responsible statement or communication.
\end{abstract}

Keywords: urban planning law; license; responsible statement; administrative control.

* Fecha de finalización del trabajo: 6 de abril de 2021. 
SUMARIO $^{1}$ : I. INTRODUCCIÓN. LA CRISIS ECONÓMICA DERIVADA DE LA COVID-19 Y LA RESPUESTA DEL LEGISLADOR URBANÍSTICO. LA DECLARACIÓN RESPONSABLE COMO SOLUCIÓN.-II. EL ÁMBITO DE ACTUACIÓN DE LA DECLARACIÓN RESPONSABLE. ¿PREVALENCIA DE LA LICENCIA COMO TÉCNICA PRIMORDIAL DE CONTROL?: 1. La limitada competencia autonómica para determinar los supuestos sometidos a declaración responsable. 2. ¿Se ha producido un cambio de paradigma en el control urbanístico otorgando la prevalencia al control ex post? 3. El limitado ámbito de las declaraciones responsables y las comunicaciones previas: 3.1. Obras de edificación de limitada entidad. 3.2. Obras de intervención sobre las edificaciones existentes o que supongan el cambio de uso que no alteren ni la edificabilidad ni la imagen. 3.3. Primera ocupación de viviendas. 3.4. Instalaciones de energía solar en edificaciones o instalaciones existentes. 4. ¿Existe algún criterio normativo para optar por la declaración responsable o por la comunicación previa? 5. ¿Están adecuadamente protegidos los derechos de terceros?-III. RÉGIMEN JURÍDICO: 1. Concepto. ¿Ejercicio inmediato o diferido? 2. ¿¿éficit de seguridad jurídica? 3. Comprobación e inspección. 4. Comprobación. La sustitución de la comprobación municipal por la actuación de una entidad externa colaboradora. 5. ¿Caducidad de la eficacia de la declaración responsable? 6. Inspección. ¿Revisión o revocación de las declaraciones responsables? 7. Restablecimiento de la legalidad infringida y responsabilidad por la comisión de infracciones urbanísticas. 8 . Anulación judicial del plan y declaraciones responsables y comunicaciones previas.-IV. BIBLIOGRAFÍA.

\section{INTRODUCCIÓN. LA CRISIS ECÓNOMICA DERIVADA DE LA COVID-19 Y LA RESPUESTA DEL LEGISLADOR URBANÍSTICO. LA DECLARACIÓN RESPONSABLE COMO SOLUCIÓN}

La práctica totalidad de las Comunidades Autónomas han adoptado modificaciones de su regulación urbanística tendentes materializar una simplificación administrativa que logre la agilización del control urbanístico y que evite que este se muestre como una rémora para la actuación de los titulares de suelo, ante una Administración lenta o paralizada. El argumento (o la excusa) explicitado se encuentra, además, en la necesidad de dar una adecuada respuesta a la crisis económica derivada de la covid- $19^{2}$, así como a las dificultades de funcionamiento de una Administración local obligada a una forzosa adaptación al teletrabajo. La respuesta adoptada ha consistido en la ampliación de los supuestos sometidos a declaración responsable o comunicación en materia de actos edificatorios y de uso del suelo ${ }^{3}$. Se opta así por estas técnicas de control urbanístico que

1 Abreviaturas utilizadas: CE: Constitución española; LJCA: Ley 29/1998, de 13 de julio, reguladora de la Jurisdicción Contencioso-Administrativa; LOE: Ley 38/1999, de 5 de noviembre, de Ordenación de la Edificación; LPAC: Ley 39/2015, de 1 de octubre, del Procedimiento Administrativo Común de las Administraciones Públicas; LRJSP: Ley 40/2015, de 1 de octubre, de Régimen Jurídico del Sector Público; TRLSRU: Real Decreto Legislativo 7/2015, de 30 de octubre, por el que se aprueba el texto refundido de la Ley de Suelo y Rehabilitación Urbana.

2 Se sigue por el legislador autonómico la senda iniciada por el legislador estatal a partir de la Ley 12/2012, de 26 de diciembre, de medidas urgentes de liberalización del comercio y de determinados servicios y la Ley 20/2013, de 9 de diciembre, de garantía de la unidad de mercado, o la Ley 9/2014, de 9 de mayo, General de Telecomunicaciones, donde se subordina el interés urbanístico a la prevalencia del ejercicio de actividades económicas. Sobre ello, Domínguez MarTín (2017: 103); Monteserín Heredia (2015: 130).

3 Decreto-ley 2/2020, de 9 de marzo, de mejora y simplificación de la regulación para el fomento de la actividad productiva de Andalucía; Ley 1/2021, de 11 de febrero, de simplificación administrativa de Aragón, 
implican una intervención (ex post) de baja intensidad para garantizar el interés público con una mínima carga burocrática. Esta opción da como resultado un proceso propio y singular de deconstrucción del sistema de control municipal previo mediante licencia ${ }^{4}$, donde se gana en predictibilidad y se potencia la responsabilidad del particular, al depender la realización de la actividad edificatoria o del uso del suelo de su propia implicación y no del albur administrativo ${ }^{5}$.

Con carácter general, la opción normativa que propugna la prevalencia del control ex post de determinados actos de edificación o uso del suelo mediante la declaración responsable o la comunicación frente al control previo de la licencia o autorización es defendida como un instrumento jurídico que favorece la libertad pero que coloca al ciudadano en una situación de relativa incertidumbre o inseguridad ${ }^{6}$, de pérdida de las garantías derivadas del procedimiento administrativo ${ }^{7}$, internalizando los riesgos de ello ${ }^{8}$. El análisis de política legislativa otorga mayor valor aquí a la reducción de cargas burocráticas y a la posibilidad de ejercer de forma inmediata el derecho (ante la incapacidad de la Administración de resolver en plazos razonables) frente a la posible mayor seguridad del interesado que obtiene un título administrativo, dotado de la presunción de validez e inmediatamente ejecutivo.

Las modificaciones incorporadas se autodefinen como estructurales por los legisladores autonómicos, afirmándose que pretenden «cambiar políticas públicas que a lo largo de los años han manifestado una inercia de resistencia al cambio y que en algunos casos han frenado el crecimiento" (Exposición de Motivos de la Ley 9/2021, de 25 de febrero, de simplificación administrativa y de apoyo a la reactivación económica de Galicia). Todas estas modificaciones legislativas se engarzan expresamente en los principios de buena regulación ${ }^{9}$ y transparencia, así como en los principios de proporcionalidad, eficacia y eficiencia. Porque el objetivo buscado no es imponer «menos Administración, sino exigir mejor Administración» (Exposición de Motivos de la Ley 1/2021, de 11 de febrero, de simplificación administrativa de Aragón). La finalidad última es reconducir «la utilización de la técnica autorizatoria a los supuestos en los que así lo exijan los ... principios de necesidad y proporcionalidad, lo que supone la reducción de gran número

Ley 1/2021, de 12 de febrero, de simplificación urbanística y medidas administrativas de Castilla-La Mancha; Ley 9/2021, de 25 de febrero, de simplificación administrativa y de apoyo a la reactivación económica de Galicia; Ley 1/2020, de 8 de octubre, por la que se modifica la Ley 9/2001, de 17 de julio, del Suelo de la Comunidad de Madrid, para el impulso y reactivación de la actividad urbanística; o la Ley 2/2020, de 27 de julio, de mitigación del impacto socioeconómico de la covid-19 en el área de vivienda e infraestructuras de la Región de Murcia.

4 Velasco Caballero (2014: 2).

5 GiFREU FonT (2014: 184).

${ }^{6}$ Muñoz Machado (2015: 233); Santamaría Pastor (2015: 11). Un análisis sobre la mayor o menor eficiencia de los controles previos y posteriores en función de la mayor facilidad para obtener la información sobre el ajuste al ordenamiento jurídico, en DOMÉNECH PASCUAL (2017: 52).

7 Casado Echarren y Serrano Martín de Vidales (2021: 9).

8 Velasco Caballero (2014: 3).

9 Sobre su alcance, GonZÁlez BuSTOS (2016: 3). 
de licencias urbanísticas existentes en la actualidad y su sustitución por un sistema de intervención administrativa posterior a través de las declaraciones responsables, con la consolidación de la colaboración pública-privada en este ámbito como garantía de su eficacia, particularmente, en los municipios que han de gestionar un elevado número de solicitudes» (Exposición de Motivos de la Ley 1/2020, de 8 de octubre, por la que se modifica la Ley 9/2001, de 17 de julio, del Suelo de la Comunidad de Madrid, para el impulso y reactivación de la actividad urbanística) ${ }^{10}$.

Una primera observación resulta necesaria. Este cambio de paradigma solo pasará del «papel a la realidad» de la actuación municipal si junto con la dimensión normativa y procedimental se afrontan cambios en la dimensión organizativa ${ }^{11}$, incorporando una estrategia global de cambio. Con la figura de la declaración responsable o la comunicación en el ámbito urbanístico no se persigue una desregularización del control del uso del suelo o las edificaciones. No se trata de una privatización de funciones públicas o de adoptar un modelo donde lo público se retire de este ámbito. Por el contrario, lo que se busca por el legislador autonómico es incorporar técnicas de intervención administrativa que posibiliten a la vez la máxima agilidad de la actuación administrativa y favorezcan el dinamismo económico y social, al tiempo que se trata de evitar que el principio de simplificación administrativa entre en colisión con otros principios o valores jurídicos (la seguridad y la gestión de riesgos, la protección ambiental, etc.). De lo que se trata es de mantener el mismo nivel de cumplimiento y, para ello, hay que compensar el relajamiento del control preventivo con una intensificación del control represivo ${ }^{12}$. Y esta finalidad solo se puede alcanzar si la Administración local cuenta con servicios de inspección y control con capacidad suficiente para asumir las funciones de comprobación, inspección y sanción en el ámbito de que se trate. En otros términos, debe existir una relación proporcional inversa entra la reducción de las cargas burocráticas y la intensificación del control expost ${ }^{13}$.

10 Donde además se precisa que «este tipo de cargas administrativas innecesarias dificultan la supervivencia de las empresas promotoras y, con ello, elevan la intensidad de la destrucción de empleo. Por ello, la actuación de los poderes públicos ha de encaminarse a mejorar la regulación, generando normas eficientes, trámites simplificados e instituciones eficaces, que faciliten el buen funcionamiento de las actividades productivas y, por tanto, del crecimiento y del desarrollo económico".

11 NúÑEZ LozANo (2015: 2), donde cuestiona si la Administración dispondrá de medios para realizar un control sistemático y no aleatorio del ejercicio de cuantos derechos y actividades se encuentran sometidos a declaración responsable y comunicación. En sentido similar, BAÑO LEÓN (2014: 1); REBOLLO PUIG (2019b: 25); Domínguez MarTín (2020: 3); Gifreu Font (2014: 184).

12 De hecho, la postergación de estos intereses públicos con los que el principio de simplificación del procedimiento entra a menudo en colisión ha llevado a reprochar que se estimulen iniciativas simplificadoras con un mero pretexto desregulador y no mediante la aplicación de metodologías que permitan tomar suficientemente en consideración todos los intereses en presencia. Sobre ello, DOMínGUEZ MARTín (2017: 118).

13 Lo que no siempre ocurre. Velasco CABAllero (2014: 3), tras constatar que el régimen de las comunicaciones previas y declaraciones responsables supone la reducción de la actividad de la Administración, precisa que será cada ayuntamiento el que «organice un sistema de inspección in situ generalizada y reiterada en el tiempo, o un modelo de vigilancia aleatorio o solo activado previa denuncia externa", lo que dependerá de decisiones organizativas. 


\section{EL ÁMBITO DE ACTUACIÓN DE LA DECLARACIÓN RESPONSABLE. ¿PREVALENCIA DE LA LICENCIA COMO TÉCNICA PRIMORDIAL DE CONTROL?}

\section{La limitada competencia autonómica para determinar los supuestos sometidos a declaración responsable}

La utilización de la figura de la declaración responsable o la comunicación como mecanismo de control administrativo ex post ${ }^{14}$ en el ámbito urbanístico no es una exigencia del derecho de la Unión Europea ${ }^{15}$. La Directiva 2006/123/CE del Parlamento Europeo y del Consejo, de 12 de diciembre de 2006, relativa a los servicios en el mercado interior excluye de su ámbito de aplicación las licencias urbanísticas y constata que la planificación urbana y la protección del entorno urbano se consideran «razones imperiosas de interés general» cuando se proyectan sobre actividades económicas ${ }^{16}$. El impacto de la Ley 20/2013, de 9 de diciembre, de garantía de la unidad de mercado en el ámbito urbanístico, ha sido hasta el momento limitado (urbanismo comercial, viviendas turísticas...). Mayor impacto presenta la Ley 12/2012, de 26 de diciembre, de medidas urgentes de liberalización del comercio y de determinados servicios, si bien limitada a los locales y establecimientos comerciales y de servicios que no superen los $750 \mathrm{~m}^{2}$, donde las obras de acondicionamiento que no requieran proyecto obra conforme a la LOE y no afecten a edificios protegidos o a bienes públicos se someten a declaración responsable ${ }^{17}$.

En este contexto, el vigente art. 11.3 TRLSRU impone para "todo acto edificatorio» (y de uso urbanístico del suelo) la verificación de un control municipal sobre su adecuación o compatibilidad con la ordenación urbanística y edificatoria aplicable a la parcela. Tal exigencia normativa debe hoy integrarse con el principio de proporcionalidad en la imposición de intervenciones administrativas (art. 4.1 LRJSP), posibilitando que el legislador autonómico, y en su desarrollo las ordenanzas municipales, opten por excluir determinadas actuaciones de ese control ${ }^{18}$, adoptando un criterio positivo de exclusión, identificando los actos no sujetos a control [art. 333 Ley 4/2017, del Suelo y de los Espacios Naturales Protegidos de Canarias ${ }^{19}$; art. 145.2.a) Ley 12/2017, de

14 Como precisa BAÑo LEÓN (2018: 49), se trata de un supuesto de autocontrol por el interesado de la normativa administrativa sujeto a una fiscalización ex post indefinida por parte de la Administración.

15 Domínguez Martín (2017: 105); González Bustos (2016: 6); García Gómez de Mercado (2020: 233); Casado Echarren y Serrano Martín de Vidales (2021: 1); Monteserín Heredia (2015: 127). Con matices, Gifreu FonT (2014: 176).

16 Rebollo Puig (2019: 7).

17 Rebollo Puig (2019: 9) precisa que se trata de obras de intervención en edificios existentes que no alteren su configuración arquitectónica por no producir una variación esencial de la composición general exterior, la volumetría, o el conjunto del sistema estructural ni cambien los usos característicos del edificio, así como el cambio de uso.

18 Sobre ello, Velasco Caballero (2021), que configura a esos actos como «libres».

19 Que excluye las actuaciones auxiliares de una obra autorizada con licencia, y las obras de conservación o reforma consistentes en la sustitución de acabados interiores o exteriores de una vivienda o local. 
Urbanismo de las Islas Baleares ${ }^{20}$; art. 160.f) Ley 9/2001, de Suelo de la Comunidad de Madrid $^{21}$; art. 215 Ley 5/2014, de Ordenación del Territorio, Urbanismo y Paisaje de la Comunidad Valenciana] ${ }^{22}$. Esa exclusión resulta completamente lógica, puesto que tales actuaciones no tienen una incidencia real externa, no viéndose comprometidos en ningún momento la salud, seguridad y bienestar de los ciudadanos como elementos justificativos del control administrativo ${ }^{23}$. No obstante, la mayor parte de la legislación autonómica sigue sometiendo todos los actos al control municipal mediante licencia o declaración responsable/comunicación.

En el ámbito urbanístico, es cierto que el legislador estatal no ha incorporado en el TRLSRU una identificación positiva de los supuestos sometidos a declaración responsable, como mecanismo para el aseguramiento de las condiciones básicas de igualdad en el ejercicio del derecho de propiedad ex art. 149.1.11. ${ }^{a} \mathrm{CE}$, al carecer de competencia para ello. Pero sí incorpora una delimitación negativa de los mismos, al establecer determinados supuestos donde se requiere de forma necesaria la tramitación del procedimiento de otorgamiento de licencia, respecto del que establece el sentido negativo del silencio. Ahí encuentran las Comunidades Autónomas un límite infranqueable de supuestos que necesariamente deben estar articulados sobre la figura de la licencia como mecanismo de control ex ante $e^{24}$.

Prima facie, la opción normativa consistente en la sustitución de la tradicional técnica administrativa de control ex ante del derecho preexistente (licencia), por otra que permite iniciar el uso del suelo sin que medie acto administrativo resolutorio (declaración responsable o comunicación) se subsume en el ámbito competencial exclusivo autonómico en materia de urbanismo (art. 148.3 CE). El Tribunal Constitucional ha afirmado que en la competencia exclusiva sobre urbanismo debe entenderse comprendido "el control de los usos del suelo" ${ }^{25}$, ya que la intervención administrativa sobre los usos del suelo, y por tanto sobre la edificación, corresponde a la competencia exclusiva de la Comunidad Autónoma en materia de urbanismo. Ahora bien, el Estado, sobre

20 Que fundamentalmente excluye las obras de escasa entidad constructiva y económica en suelo urbano con presupuesto inferior a 3.000 euros, y no pueden acumularse en un mismo año obras superiores a este presupuesto en una misma ubicación, que no requieren proyecto ni dirección técnica y se desarrollan en su integridad en el interior de las edificaciones existentes, a excepción de las que se ejecuten en edificios declarados como bienes de interés cultural o catalogados, y en las edificaciones o construcciones en situación de fuera de ordenación.

21 En la redacción dada por la Ley 1/2020, donde se excluyen de cualquier tipo de control «los acabados interiores, tales como solados y alicatados, o las reparaciones de cubiertas».

22 Donde se excluye fundamentalmente las actuaciones auxiliares de la realización de una obra autorizada por licencia.

23 Como señala Rebollo Puig (2019a: 20), estas actuaciones tienen una "potencialidad de vulneración urbanística... nula o ínfima».

24 Rebollo Puig (2019a: 9), quien precisa que aquí el legislador estatal ha incorporado implícitamente el juicio de proporcionalidad, al considerar que la tutela de interés general en esos supuestos no puede lograrse a través de técnicas menos restrictivas, donde el control ex post «llegaría demasiado tarde para ser realmente eficaz». En similares términos, Casado Echarren y Serrano Martín de Vidales (2021: 6).

25 Sentencia del Tribunal Constitucional 143/2017, FJ $2 .^{\circ}$ 
la base del art. 149.1.18. ${ }^{\text {a }} \mathrm{CE}$, que le atribuye la competencia para fijar las bases del régimen jurídico de las Administraciones públicas ${ }^{26}$, puede imponer «que exista una intervención administrativa de conformidad, aprobación o autorización que habrá de ser establecida por la legislación autonómica» ${ }^{27}$. El Tribunal Constitucional identifica esa exigencia de la normativa estatal como «una norma de funcionamiento que disciplina la actuación de las entidades locales, incidiendo directamente en los derechos de los particulares y en la forma de ejercitarlos, y por tanto, en su tratamiento común por las administraciones públicas». Norma que presenta un claro contenido básico ${ }^{28}$ puesto que «establece un mínimo común, justificado por la complejidad técnica del uso y los valores a proteger — salud, seguridad y bienestar de los ciudadanos — dejando margen a las Comunidades Autónomas para establecer, en función del tipo de edificación de que se trate, cuál de las formas de intervención resultará preceptiva». El Estado puede, también y de forma indirecta, imponer un tipo concreto de instrumento de control, la licencia para determinados actos de uso del suelo en atención a su relevancia, sobre su competencia para fijar las bases del régimen jurídico de las Administraciones públicas, sin que ello agote la posibilidad de desarrollo de la legislación básica por parte de las Comunidades Autónomas, puesto que estas pueden «establecer el régimen autorizatorio atendiendo a sus peculiaridades, e incluso extenderlo a otro tipo de actividades y usos urbanísticos» ${ }^{29}$. Además, el Estado también puede fijar el sentido negativo del silencio sobre la base de la competencia para incorporar especialidades ratione materiae en el procedimiento administrativo de otorgamiento de licencias, que es competencia autonómica, sobre la base del art. 149.1, apartados 16, 21, 23 y 25 de la Constitución ${ }^{30}$.

Por tanto, respecto de los actos de uso o edificación sometidos a control municipal, estos pueden estar sometidos a la obtención previa de una licencia municipal de obras. La licencia urbanística se configura como un acto configurador mediante el que se levanta la prohibición general preventiva de edificar prevista en la norma hasta que la Administración municipal controle previamente la legalidad del proyecto edificatorio propuesto. Aquí la normativa prohíbe con carácter general la actuación únicamente con una finalidad preventiva, por lo que la licencia solo restablece el ámbito de libertad que la norma ha limitado provisionalmente en función del interés público protegido. Resulta necesario que la Administración dicte una resolución, de contenido reglado (o esta se obtenga por silencio positivo), para que el particular pueda ejercer un derecho cuya titularidad ya le correspondía, pero que hasta ese momento está prohibido ${ }^{31}$.

${ }^{26}$ Por ello resulta correcta la crítica de NúÑEZ LOZANO (2015: 6) sobre la regulación básica de esta figura en la LPAC y no en la LRJSP.

27 Sentencia del Tribunal Constitucional 143/2017, FJ 21.

28 Domínguez Martín (2020: 7), dado que se establece un mínimo común, justificado por la complejidad técnica del uso y los valores a proteger (salud, seguridad y bienestar), disponiendo las Comunidades Autónomas de un margen para establecer, en función del tipo de edificación de que se trate, cuál de las formas de intervención resultará preceptiva.

29 Sentencia del Tribunal Constitucional 143/2017, FJ 22.

30 Sentencia del Tribunal Constitucional 143/2017, FJ 23.

31 Chinchilla Peinado (2008: 50). 
Pero tales actos también pueden estar sometidos a una comunicación o una declaración responsable. Las mismas presuponen también la existencia de una prohibición general preventiva de realizar actos de edificación o de uso del suelo prevista en la norma. Pero aquí la prohibición no se levanta mediante el dictado de un acto configurador por la Administración. Al contrario, dicha prohibición preventiva simplemente decae si la Administración no ejerce su veto (represivo) dictando una resolución desde la comunicación o declaración del particular, siendo esa actuación del particular ${ }^{32}$ la que permite el ejercicio libre de la actividad, bien de forma inmediata, bien transcurrido el plazo normativamente establecido para que la Administración controle su adecuación a derecho. La comunicación o declaración responsable efectuada por el particular, que no puede conceptuarse como una solicitud, no requiere una resolución administrativa que ponga fin al procedimiento decidiendo sobre el fondo del asunto (declarando la compatibilidad o incompatibilidad de lo proyectado con el régimen urbanístico aplicable a la finca, obtenida en su caso por silencio administrativo), a tenor del art. 69 LPAC $^{33}$. La relación jurídico-administrativa se genera así al margen del procedimiento administrativo ${ }^{34}$. Los efectos de la declaración o la comunicación no se imputan a la Administración, sino que derivan directamente de la ley ${ }^{35}$. De ahí que metodológicamente resulta acertado afirmar que aquí no existe un título administrativo habilitante ${ }^{36}$. Por el contrario, no resulta correcto afirmar que no «surge» un derecho para el sujeto particular ${ }^{37}$. En consecuencia, la Administración municipal, una vez presentada la comunicación o declaración responsable, si no procede el requerimiento de subsanación o de solicitud de licencia ordinaria, sin perjuicio de la liquidación de la tasa municipal que proceda y, en su caso, de la notificación que sea necesaria posteriormente relativa a la emisión de una diligencia o documento declarativo de la actuación urbanística comunicada o declarada (que en ningún caso tendrá la consideración de resolución, sino de acto simplemente certificante, al no suponer por sí mismo una decisión vinculante), no debe realizar actuación alguna para reconocer el derecho del interesado.

\section{2. ¿ंSe ha producido un cambio de paradigma en el control urbanístico otorgando la prevalencia al control ex post?}

Una primera pregunta que surge es si se ha producido realmente un «vuelco sustancial» del sistema de control de la actividad urbanística, donde la regla general es la

32 BAÑo LEÓN (2014: 3), quien precisa que «La declaración es un requisito que legitima el ejercicio de la actividad exigido por la norma administrativa». En sentido similar, DOMÍNGUEZ MARTín (2020: 4).

33 Rebollo Puig (2019: 63); Domínguez Martín (2017: 112); GonzÁlez Bustos (2016:19); Casado ECHARREN y SERrano Martín de Vidales (2021: 8).

34 BaÑo León (2018: 48).

35 BAÑo LeÓN (2014: 3).

36 Rebollo Puig (2019b: 69).

37 Como propone Rebollo Puig (2019b: 72) afirmando que la declaración o comunicación del interesado solo presenta un «escaso valor que consiste únicamente en haber cumplido con una carga formal». 
declaración responsable (o la comunicación) y la excepción la licencia, que solo juega un papel residual, como se ha afirmado por algún autor ${ }^{38}$. Esa afirmación no resulta del todo precisa. La licencia, en cuanto mecanismo de control previo, sigue siendo el instrumento técnico de control de las actuaciones de uso del suelo y edificación más relevantes, en términos cualitativos, aunque quizá no las más numerosas ${ }^{39}$. Este análisis debe proyectarse sobre las distintas actuaciones sobre el medio urbano. En las actuaciones de nueva urbanización, de renovación y reforma de la urbanización y de dotación, la licencia prima facie sigue siendo el instrumento prevalente, aunque no exclusivo, para las actuaciones edificatorias. Solo en las actuaciones edificatorias que no impliquen la demolición y nueva edificación tendrá prevalencia la declaración responsable o la comunicación.

Con carácter general, la legislación autonómica identifica y acota expresamente el ámbito de actuación de la declaración responsable o de la comunicación. Solo excepcionalmente se adopta un criterio residual, sometiendo a dicha técnica a todos aquellos «actos de edificación y uso del suelo y del subsuelo no sujetos a licencia» (parcialmente art. 162 Ley 11/2018, de Ordenación Territorial y Urbanística Sostenible de Extremadura; y art. 142.3 Ley 2/2016, de 10 de febrero, del suelo de Galicia). Solo en un caso, la legislación autonómica permite que su opción por la declaración responsable sea «desplazada" por el ayuntamiento a través de la correspondiente ordenanza municipal mediante el sometimiento de las actuaciones inicialmente sometidas a declaración responsable mediante la previa obtención de licencia (art. 214.3 Ley 5/2014, de Ordenación del Territorio, Urbanismo y Paisaje, de la Comunidad Valenciana ${ }^{40}$. Igualmente, en un solo supuesto, la legislación autonómica permite que la previsión legal de exigencia de licencia previa sea desplazada por una norma reglamentaria (art. 148.2 Ley 12/2017, de Urbanismo de las Islas Baleares, que reconoce esa competencia a los Consejos Insulares). Estas últimas opciones resultan criticables, debiendo ser las normas con rango de ley las que determinen el sometimiento de las concretas actuaciones edificatorias o de uso del suelo a comunicación o a declaración ${ }^{41}$. La garantía de un adecuado juicio de proporcionalidad y el principio de seguridad jurídica en el establecimiento de las medidas de intervención menos restrictivas así lo demandan. Obviamente esa no es la función ni del planeamiento ni de las ordenanzas de edificación ${ }^{42}$.

No obstante, debe destacarse la falta de incorporación expresa de esta figura en las leyes urbanísticas de las Comunidades Autónomas de Asturias y La Rioja, cuyas leyes sobre urbanismo no incorporan regulación alguna al respecto ${ }^{43}$. A su vez, en el caso de Cantabria, se remite la Ley a la concreta regulación por ordenanza municipal para so-

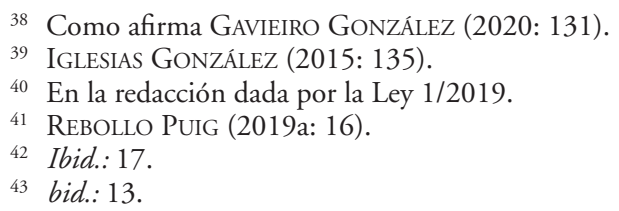


meter las obras menores a control por medio de licencia o por declaración responsable (art. 183.4 Ley 2/2001, de Ordenación Territorial y Régimen Urbanístico del Suelo de Cantabria ${ }^{44}$. En la misma línea, País Vasco remite a la ordenanza municipal la posibilidad de someter a comunicación la ejecución de obras de escasa entidad técnica, para las cuales no sea necesaria la presentación de proyecto técnico y para aquellas otras actuaciones que prevean las propias ordenanzas [arts. 206.1.b) y 207.5 Ley 2/2006, de 30 de junio, de Suelo y Urbanismo].

\section{El limitado ámbito de las declaraciones responsables y las comunicaciones previas}

Procede analizar los supuestos donde las Comunidades Autónomas han optado por incorporar la figura de la declaración responsable o la comunicación, configurándolos como ámbitos privados que trascienden al interés público ${ }^{45}$. Se anticipa que el juicio de proporcionalidad efectuado por los diferentes legisladores autonómicos puede calificarse, en su mayoría, de razonable ${ }^{46}$. Y ello porque en los supuestos identificados el control a posteriori no se revela como ineficaz por excesivamente tardío.

\subsection{Obras de edificación de limitada entidad}

Las diversas leyes autonómicas someten a declaración responsable/comunicación la ejecución de «Obras de edificación de nueva planta de escasa entidad constructiva y sencillez técnica que no tengan, de forma eventual o permanente, carácter residencial ni público y se desarrollen en una sola planta» [art. 169.bis.1.a) Ley 7/2002, de 17 de diciembre, de Ordenación Urbanística de Andalucía ${ }^{47}$; art. 227.2. a) Decreto Legislativo 1/2014, por el que se aprueba el Texto Refundido de la Ley de Urbanismo de Aragón; 157.1.a) Decreto Legislativo 1/2010, por el que se aprueba el Texto Refundido de la Ley de Ordenación del Territorio y de la Actividad Urbanística de Castilla-La Mancha ${ }^{48}$; art. 162.b) Ley 11/2018, de Ordenación Territorial y Urbanística Sostenible de Extremadura; art. 155.a) Ley 9/2001, de Suelo de la Comunidad de Madrid ${ }^{49}$; art. 148.1 Ley 12/2017, de Urbanismo de Islas Baleares; art. 264.2.d) Ley 13/2015, de Ordenación Territorial y Urbanística de Murcia ${ }^{50}$. Se trata, por tanto, de edificaciones que no requieren proyecto técnico conforme a la LOE. En algún caso, esta figura se concreta a las obras de escasa entidad o dimensión, u obras menores, que se determinen en las

\footnotetext{
44 En la redacción dada por la Ley 12/2020.

45 BAÑo LEÓn (2014: 18).

46 En gran medida siguen las propuestas formuladas por REBOLLO PUIG (2019a: 18).

47 En la redacción dada por el Decreto-Ley 2/2020.

48 En la redacción dada por la Ley 1/2021.

49 En la redacción dada por la Ley 1/2020.

50 En la redacción dada por la Ley 4/2020.
} 
correspondientes ordenanzas municipales (art. 192 Decreto Foral Legislativo 1/2017, de Ordenación del Territorio y Urbanismo de Navarra).

\subsection{Obras de intervención sobre las edificaciones existentes o que supongan el cambio de uso que no alteren ni la edificabilidad ni la imagen}

En segundo lugar se someten a declaración responsable o comunicación las obras de ampliación, modificación, reforma, rehabilitación o demolición sobre los edificios existentes que no produzcan una variación esencial de la composición general exterior, la volumetría, la envolvente global o el conjunto del sistema estructural. [art. 169.bis.1.b) Ley 7/2002, de 17 de diciembre, de Ordenación Urbanística de Andalucía ${ }^{51}$; art. 227.2.b) Decreto Legislativo 1/2014, por el que se aprueba el Texto Refundido de la Ley de Urbanismo de Aragón; art. 332.1, apartados a), b) y d) Ley 4/2017, de Suelo y Espacios Naturales de Canarias; art. 157.1.b) Decreto Legislativo 1/2010, por el que se aprueba el Texto Refundido de la Ley de Ordenación del Territorio y de la Actividad Urbanística de Castilla-La Mancha ${ }^{52}$; art. 105.bis.1.a) Ley 5/1999, de Urbanismo de Castilla y León ${ }^{53}$; art. 162.a) Ley 11/2018, de Ordenación Territorial y Urbanística Sostenible de Extremadura; art. 155.b) Ley 9/2001, de Suelo de la Comunidad de Madrid ${ }^{54}$; art. 264.2, apartados a), b), y c) Ley 13/2015, de Ordenación Territorial y Urbanística de Murcia ${ }^{55}$. Se trata, por tanto, de actuaciones de rehabilitación o reforma en edificaciones en la ciudad existente configuradas como actuaciones edificatorias (art. 7.2. TRLSRU), en las que no se alteran ni los parámetros de «edificabilidad, ocupación y altura» ni el conjunto del sistema estructural ${ }^{56}$. Algunas comunidades incluyen aquí también el cambio de uso dentro de los compatibles o alternativos previstos por el planeamiento aplicable. Aquí puede surgir un problema si el cambio de uso afecta al uso característico de la edificación, donde debe acreditarse, por referencia al nuevo uso, que se cumple la normativa técnica de seguridad y habitabilidad previstas en la normativa de edificación ${ }^{57}$.

\subsection{Primera ocupación de viviendas}

Igualmente se somete a declaración responsable, siguiendo la senda abierta por el legislador estatal ${ }^{58}$ [arts. 11.5 y 28.1.b) TRLSRU] ${ }^{59}$, la primera ocupación de las edifica-

51 En la redacción dada por el Decreto-Ley 2/2020.

52 En la redacción dada por la Ley $1 / 2021$.

53 En la redacción dada por la Ley $7 / 2014$.

54 En la redacción dada por la Ley $1 / 2020$.

55 En la redacción dada por la Ley 4/2020.

56 Zamorano Weis (2020: 26).

57 Casado Echarren y Serrano Martín de Vidales (2021: 8).

58 Que a su vez ha incorporado la regulación previa de varias Comunidades Autónomas. Sobre ello, Monteserín Heredia (2015: 145).

59 Rebollo Puig (2019a: 9), quien señala que el legislador estatal deberá adaptar su legislación sobre registros y documentos notariales a esa legislación autonómica. 
ciones de nueva planta y de las casas prefabricadas» [art. 169.bis.1, apartados $c$ ) y d) Ley 7/2002, de Ordenación Urbanística de Andalucía ${ }^{60}$; art. 227.2.d) Decreto Legislativo 1/2014, por el que se aprueba el Texto Refundido de la Ley de Urbanismo de Aragón; art. 332.1.c) Ley 4/2017, de Suelo y Espacios Naturales de Canarias; art. 157.1, apartados c) y d) Decreto Legislativo 1/2010, por el que se aprueba el Texto Refundido de la Ley de Ordenación del Territorio y de la Actividad Urbanística de Castilla-La Mancha ${ }^{61}$; art. 105.bis.1.j) Ley 5/1999, de Urbanismo de Castilla y León ${ }^{62}$; art. 162.j) Ley 11/2018, de Ordenación Territorial y Urbanística Sostenible de Extremadura; art. 155.c) Ley 9/2001, de Suelo de la Comunidad de Madrid ${ }^{63}$; art. 264.2.f) Ley 13/2015, de Ordenación Territorial y Urbanística de Murcia] ${ }^{64}$.

Aquí se requiere que la edificación esté concluida y lo haya sido conforme a la licencia de edificación previamente concedida ${ }^{65}$. El problema estriba en la regulación del art. 28.1.b) TRLSRU ${ }^{66}$. Ahí el legislador estatal (sectorial) urbanístico precisa que el Registrador de la Propiedad exigirá, para autorizar la escritura de declaración de obra nueva terminada, que se presente por el interesado el documento que acredite haber presentado la declaración responsable (copia emitida por el registro de entrada) y que haya «transcurrido el plazo establecido para que pueda iniciarse la correspondiente actividad, sin que del Registro de la Propiedad resulte la existencia de resolución obstativa alguna». Se está imponiendo así a las Comunidades Autónomas la obligación de diferir, en este caso concreto, el inicio del uso de la edificación respecto del momento de presentación de la declaración responsable, como garantía de la tutela de los terceros adquirentes.

Evidentemente, la calificación registral positiva efectuada por el Registrador de la Propiedad no elimina la facultad de comprobación e inspección del ayuntamiento, puesto que la misma no prejuzga el ajuste de la obra terminada a la normativa urbanística aplicable ${ }^{67}$. No obstante, este es el supuesto más problemático en la práctica, al poder producirse situaciones de primera ocupación parcial de un edificio, o de vinculación con la ejecución de las obras de urbanización, o de edificaciones en situación de fuera de ordenación o asimilados, donde los derechos e intereses de terceros pueden verse gravemente afectados ante la orden de cese dictada por el ayuntamiento como consecuencia de sus facultades de comprobación ${ }^{68}$.

60 En la redacción dada por el Decreto-Ley 2/2020.

${ }_{61}$ En la redacción dada por la Ley 1/2021.

62 En la redacción dada por la Ley $7 / 2014$.

63 En la redacción dada por la Ley $1 / 2020$.

64 En la redacción dada por la Ley 4/2020.

65 Zamorano WeIs (2020: 28).

${ }^{66}$ La declaración responsable no es título idóneo para inscribir la declaración de obra nueva, conforme a la Resolución de la DGRN de 26 de febrero de 2018. Sobre la misma, CASADO ECHARREN y SERRANO MARTín DE Vidales (2021: 13).

67 GaVieIRo GonZÁlez (2020: 134).

68 Como pone de relieve Monteserín Heredia (2015: 146), quien propugnaba la exigencia de licencia en estos supuestos. 


\subsection{Instalaciones de energía solar en edificaciones o instalaciones existentes}

Se someten a declaración responsable o comunicación la ubicación de instalaciones de aprovechamiento de energía solar mediante paneles fotovoltaicos destinadas a autoconsumo sobre cubierta y edificaciones y pérgolas de aparcamientos de vehículos o en los espacios libres privados no susceptibles de ocupación de las parcelas [art. 227.2, apartados $f$ ) y $g$ ) Decreto Legislativo $1 / 2014$, por el que se aprueba el Texto Refundido de la Ley de Urbanismo de Aragón ${ }^{69}$; art. 332.1, apartados p), q) y r) Ley 4/2017, de Suelo y Espacios Naturales de Canarias; art. 157.1.e) Decreto Legislativo 1/2010, por el que se aprueba el Texto Refundido de la Ley de Ordenación del Territorio y de la Actividad Urbanística de Castilla-La Mancha ${ }^{70}$; art. 105.bis.1.k) Ley 5/1999, de Urbanismo de Castilla y León ${ }^{71}$; art. 55.2.b) Ley 9/2021, de simplificación administrativa y de apoyo a la reactivación económica de Galicia; art. 148.4 Ley 12/2017, de Urbanismo de Islas Baleares; art. 264.2.g) Ley 13/2015, de Ordenación Territorial y Urbanística de Murcia] ${ }^{72}$. En esta misma línea se sitúa la instalación de puntos de recarga de vehículos eléctricos en edificios de uso colectivo [art. 227.2.h) Decreto Legislativo 1/2014, por el que se aprueba el Texto Refundido de la Ley de Urbanismo de Aragón; art. 332.1.s) Ley 4/2017, de Suelo y Espacios Naturales de Canarias; art. 157.1.f) Decreto Legislativo 1/2010, por el que se aprueba el Texto Refundido de la Ley de Ordenación del Territorio y de la Actividad Urbanística de Castilla-La Mancha ${ }^{73}$; art. 148.4 Ley 12/2017, de Urbanismo de Islas Baleares]. O la implantación de aislamiento térmico de las edificaciones existentes y la instalación de dispositivos bioclimáticos adosados a las fachadas o cubiertas de las edificaciones existentes [art. 332.1, apartados ñ) y o) Ley 4/2017, de Suelo y Espacios Naturales de Canarias].

\section{4. ¿EXISTE ALGÚN CRITERIO NORMATIVO PARA OPTAR POR LA DECLARACIÓN RESPONSABLE O POR LA COMUNICACIÓN PREVIA?}

El análisis (superficial y sintético) efectuado conduce a una segunda pregunta: ¿Existe algún criterio normativo que determine la preferencia por una u otra forma de

69 Que no obstante, las limita a los supuestos las instalaciones no superen un metro y medio de altura desde el plano de la cubierta, o, en el caso de cubierta inclinada, cuando los paneles se coloquen pegados a la cubierta en paralelo o no superando el metro de altura, excepto en edificios protegidos por razones patrimoniales u otras que requieran informes sectoriales específicos. Además, los espacios ocupados por las instalaciones mencionadas no computarán a efectos del volumen edificable de la parcela ni de las distancias mínimas de la edificación a los límites de la parcela, a otras edificaciones o en la vía pública. Los elementos auxiliares de las instalaciones, como las estructuras de apoyo o pérgolas, serán considerados partes inherentes de las instalaciones de generación solar.

70 En la redacción dada por la Ley 1/2021.

71 En la redacción dada por la Ley 7/2014.

72 En la redacción dada por la Ley 4/2020.

73 En la redacción dada por la Ley 1/2021. 
control a posteriori? Evidentemente no. Las dos figuras, al menos en la regulación positiva incorporada tanto a la LPAC como a las normas autonómicas, presentan perfiles similares $^{74}$. La única diferencia sustantiva es de matiz. En la declaración responsable el interesado simplemente explicita al ayuntamiento que cumple bajo su responsabilidad los requisitos establecidos en la normativa vigente para realizar uno de los actos de transformación, construcción, edificación o uso del suelo, vuelo o subsuelo y que dispone de la documentación que así lo acredita, en su caso suscrita por el técnico competente, que podrá ser puesta a disposición de la entidad local si la requiere, sin perjuicio de la aportación voluntaria de la documentación acreditativa del cumplimiento de los requisitos (p. ej., Madrid) ${ }^{75}$. Por el contrario, en la comunicación se pone en conocimiento del ayuntamiento que se reúnen los requisitos para realizar un acto de transformación, construcción, edificación o uso del suelo, el vuelo o el subsuelo y se aporta la documentación ${ }^{76}$ que acredita tales extremos (p. ej., Canarias) ${ }^{77}$. En ambos casos, donde se identifica (describe) la actuación a realizar, el control administrativo se difiere a un momento posterior. Ahora bien, esta diferenciación contenida en la LPAC se difumina en la legislación autonómica, en unos casos exigiendo que a la declaración responsable se adjunte la documentación pertinente, fundamentalmente el proyecto de obras o la memoria que describa el proyecto (p. ej., Castilla y León $)^{78}$. Y en otros estableciendo

74 Así Rebollo Puig (2019a: 21); Domínguez Martín (2020: 2).

75 Art. 156 Ley 9/2001. El precepto determina que «el documento de declaración responsable urbanística deberá contener: a) Los datos previstos en la legislación en materia procedimental para las solicitudes de inicio de procedimientos a instancia del interesado. b) La identificación de la actuación urbanística a realizar, sus características y su ubicación. c) Manifestación expresa y bajo su responsabilidad, del cumplimiento de los requisitos exigidos por la normativa aplicable. En particular deberá manifestarse que la actuación pretendida no se realiza sobre bienes que dispongan de algún tipo de protección de carácter ambiental o histórico-artístico, ya sea total o de elementos o partes objeto de protección, regulada a través de norma legal o documento urbanístico. De igual forma, deberá manifestarse por el interesado que está en posesión de la documentación que acredite el cumplimiento de dicha normativa, y que la pondrá a disposición del ayuntamiento en el caso de ser requerida. Voluntariamente podrán aportarse copias de tales documentos. d) El compromiso expreso de mantener el cumplimiento de dichos requisitos durante el periodo de tiempo inherente a la realización de la actuación objeto de la declaración. e) Copia de las autorizaciones emitidas por otras Administraciones que, en su caso, fueran exigibles. f) Documentación técnica suscrita por técnico competente y visada por el colegio profesional competente, cuando así venga exigido por la legislación aplicable».

${ }_{76}$ Frente al sentido correcto del art. 69 LPAC, donde la comunicación queda reservada para el ejercicio de derechos o actividades que no requieren la acreditación documental de la concurrencia de los requisitos establecidos en las normas, como precisa NúŃEZ LOZANO (2015: 3).

77 Art. 349 Ley 4/2017. Allí se precisa que «La comunicación previa vendrá integrada por un acto documentado del interesado poniendo en conocimiento de la administración competente la actuación proyectada, en los términos y con la documentación complementaria... En su caso, se deberá acompañar a la comunicación previa: a) Proyecto suscrito por técnico competente, cuando fuere preceptivo según la normativa sectorial aplicable para la realización de la actuación edificatoria o constructiva comunicada, con sucinto informe emitido por el redactor que acredite el cumplimiento de la normativa exigible. b) Título habilitante de la ejecución de la obra o edificación y certificado final de la misma expedido por técnico competente, acreditativo de que la obra se ha ajustado al proyecto autorizado, en los supuestos de comunicación previa a la primera ocupación de edificaciones...".

78 Arts. 105.ter y 105.quater Ley 5/1999, donde se establece que «la declaración responsable es el documento mediante el cual su promotor manifiesta, bajo su exclusiva responsabilidad, que los actos a los que 
que en la comunicación se incorporará «la declaración de que concurren los requisitos administrativos aplicables» (p. ej., Aragón) ${ }^{79}$. O bien estableciendo para ambas técnicas la misma documentación (p. ej., Castilla-La Mancha) ${ }^{80}$. Por tanto, la opción por una u otra técnica no responde a criterios técnico-normativos ${ }^{81}$, sino que responde a criterios de política legislativa y a una utilización intercambiable (y en la mayor parte de las ocasiones, errónea) de ambas técnicas por el legislador autonómico.

\section{5. ¿¿ESTÁN ADECUADAMENTE PROTEGIDOS LOS DERECHOS DE TERCEROS?}

Inmediatamente conectada con esta disyuntiva surge la cuestión de si con la elección de la declaración responsable o la comunicación en el ámbito urbanístico por el legislador autonómico se vulnera la prohibición de defecto de actuación a través de un procedimiento administrativo para proteger derechos fundamentales de terceros frente a las inmisiones derivadas de los actos edificatorios o de uso del suelo amparados en una declaración responsable o en una comunicación ${ }^{82}$. La protección del derecho de propiedad (del concepto de domicilio en los términos del art. 1 del Protocolo Adicional núm. 1 del Convenio Europeo de Derechos Humanos, y su dimensión ambiental frente a ruidos, olores... etc.) de posibles terceros afectados debe ser tenida en cuenta por el

se refiere cumplen las condiciones prescritas en la normativa aplicable, que posee la documentación técnica exigible que así lo acredita», debiendo presentarse «acompañada de la siguiente documentación: a) Proyecto de obras, cuando sea legalmente exigible. en otro caso bastará una memoria que describa de forma suficiente las características del acto. b) Copia de las autorizaciones de otras administraciones que sean legalmente exigibles, en su caso".

79 Art. 228 Decreto Legislativo 1/2014.

${ }^{80}$ Art. 158.2 Decreto Legislativo 1/2010, donde exige incorporar en ambos casos los siguientes documentos: «a) Documentación gráfica expresiva de la ubicación del inmueble objeto de la actuación a realizar y descripción suficiente de esta. b) Proyecto suscrito por técnico competente y visado por el colegio profesional correspondiente, cuando fuere preceptivo según la normativa sectorial aplicable para la realización de la actuación edificatoria o constructiva comunicada. c) Justificación técnica del cumplimiento de la legislación vigente y adecuación a la ordenación territorial y urbanística. d) Los permisos y autorizaciones que requiera el acto, la operación o la actividad de que se trate y que vengan exigidos por la normativa en cada caso aplicable. $e$ ) Si las obras afectan a un inmueble con actividad en funcionamiento, se aportará copia auténtica de las licencias municipales habilitadoras de la actividad que se venga desarrollando en el mismo. $f$ ) Justificante de la liquidación de los tributos y demás ingresos de derecho público que correspondan».

81 Rebollo Puig (2019a: 22) muestra su preferencia por la declaración responsable, al considerar que «la declaración responsable es una carga ligeramente más gravosa que la comunicación que formaliza algo más solemnemente la autoevaluación y los compromisos del particular». A su vez, MONTESERín Heredia (2015: 123) considera que la declaración se reserva para los supuestos donde pueden verse afectados intereses públicos o de terceros.

82 En los sugerentes términos planteados por BAÑo LEÓN (2018: 54), y su dura crítica al juicio de proporcionalidad efectuado por el legislador cuando ignora las posibles relaciones jurídicas multipolares, donde «la renuncia del legislador al procedimiento en aras de la libertad de iniciativa económica se convierte en renuncia del legislador a proteger preventivamente los demás derechos fundamentales concernidos». En esta línea, NúNEZ LOZANO (2015: 5). 
legislador, estatal o autonómico, cuando decide la sustitución de la licencia urbanística (que articula un control de legalidad previo sobre la base de un procedimiento administrativo donde los terceros pueden defender sus derechos e intereses). Solo si tales derechos resultan garantizados con un idéntico nivel de protección y eficacia, la opción por las técnicas de control ex post será adecuada.

El ejemplo de las denominadas "cocinas fantasma» (dark kitchen) que proliferan en Madrid o Barcelona, ubicadas en pequeños locales en los bajos de viviendas residenciales colectivas sobre la base de una simple declaración responsable, cuestiona el juicio de proporcionalidad efectuado por el legislador. Aquí la posibilidad de defensa del tercero solo puede producirse una vez que se ha producido la inmisión en la esfera de los derechos afectados. No existe una evaluación preventiva y ponderativa de los derechos en conflicto a través del procedimiento administrativo (trámite de audiencia) ${ }^{83}$. Y solo cabe reaccionar frente a tal inmisión provocando un procedimiento de inspección por parte del ayuntamiento. A ello se une que el reconocimiento de la acción popular en materia de urbanismo no resuelve la articulación de los mecanismos de defensa de los terceros (solo se proyecta sobre la legitimación) ${ }^{84}$.

Aun cuando el acto edificatorio o de uso del suelo que se anuda a la declaración responsable o a la comunicación no puede afectar a los derechos de terceros, debe ser «neutral ${ }^{85}$ respecto de los mismos, lo cierto es que las técnicas de control ex post suponen la desaparición de los derechos procedimentales de los terceros interesados ${ }^{86}$. La tutela primaria (preventiva) de los terceros debe contenerse, en primer lugar, en el propio instrumento de planeamiento, al regular las actuaciones edificatorias o usos que estarán sometidos a declaración responsable o comunicación desde la perspectiva de su consideración como usos permitidos o prohibidos sobre determinadas parcelas ${ }^{87}$ (p. ej., el plan puede excluir el uso de las dark kitchen en los locales de viviendas residenciales colectivas en altura; o excluir la instalación de barbacoas permanentes en determinados lugares de los patios de viviendas unifamiliares adosadas). Ahí el planificador ha debido concretar el juicio ponderativo sobre los posibles derechos e intereses afectados efectuados con nivel general por el legislador (estatal o autonómico), pudiendo adoptar decisiones motivadas de planificación dirigidas a la protección de los derechos de terceros y al control del entorno urbano, evitando su degradación ${ }^{88}$. Se trata de plasmar una actividad ex ante

83 BAÑo LeÓN (2018: 57).

84 Rebollo Puig (2019b: 36).

85 García Gómez de Mercado (2020: 231); GonzÁlez Bustos (2016: 21).

86 BAÑo LeÓN (2014: 12).

87 En contra, Casado Echarren y Serrano Martín de Vidales (2021: 6), quienes consideran que las leyes autonómicas impiden modulaciones y especificaciones por parte de la regulación municipal. Ello puede ser correcto cuando la actuación está concretamente definida en la ley (p. ej., paneles solares), pero no cuando la densidad normativa es débil y requiere la concreción del planeamiento.

${ }_{88}$ Esta es la postura afirmada por la STS de 19 de noviembre de 2020 (ECLI:ES:TS:2020:3842), que considera adecuada la calificación de las viviendas turísticas como un uso de equipamiento y no residencial por parte del instrumento de planeamiento, limitando con ello la eficacia de la declaración responsable establecida 
de definición y determinación de los supuestos concretos sometidos a declaración responsable y comunicación, así como sus condiciones y límites ${ }^{89}$. Protección de terceros que no puede incorporarse en una simple ordenanza municipal de actividades ${ }^{90}$.

Además, desde la perspectiva organizativa y sobre la base del art. 84.ter LRBRL, esa tutela primaria requiere la existencia de programas efectivos y obligatorios de inspección, cuando menos, en los supuestos donde pueda existir un riesgo potencial o real para la salud, el medio ambiente o la seguridad ${ }^{91}$. Se requiere así una decisión organizativa dirigida que, al menos, concentre los recursos de comprobación e inspección hacia aquellos supuestos donde los derechos de terceros puedan verse afectados y se efectúe la comprobación en un plazo tempestivo. Ello ocurre, por ejemplo, en los supuestos de la primera ocupación o utilización de las edificaciones, donde expresamente el legislador estatal [art. 11.5 y 28.1.b) TRLSRU] difiere la inscripción registral de la declaración de obra nueva a que haya transcurrido el plazo «de verificación». Junto a ello, debe situarse la actuación de los técnicos redactores de los proyectos, cuando sea necesario, y de las entidades de certificación (con intervención obligatoria u opcional), como sujetos cuya actividad de confirmación de la corrección del proyecto debe adquirir una mayor relevancia jurídico-pública ${ }^{92}$.

La tutela secundaria (reactiva) de los terceros se articula sobre la figura de la denuncia y el reconocimiento de su derecho al trámite en el procedimiento de inspección, y frente al que podrá reaccionar si no es estimado ${ }^{93}$. No se trata de un recurso frente a la inactividad administrativa (art. 29.1 LJCA), sino que lo que se reclama de la Administración local es que ordene el cese (acto administrativo prohibitivo de la actividad privada), porque no es conforme con el ordenamiento público. Frente al acto expreso o presunto desestimatorio cabrá un recurso contencioso-administrativo en el que se pretenda esa prohibición ${ }^{94}$. Los derechos de los terceros solo estarán adecuadamente protegidos si se les reconoce el derecho a solicitar la inspección, cuando esta no se ha llevado a cabo, y

por la legislación sectorial en materia de turismo. En la misma línea, p. ej., STSJ de Madrid de 22 de septiembre de 2020 (ECLI:ES:TSJM:2020:11502).

89 Domínguez Martín (2017: 118).

90 STSJ de la Comunidad Valenciana de 26 de enero de 2021 (ECLI:ES:TSJCV:2021:23), dado que «son los instrumentos de planeamiento, y no las ordenanzas municipales, los que pueden ordenar el uso del suelo del municipio... las únicas determinaciones en materia de urbanismo que puede regular una ordenanza municipal son las referidas a los aspectos morfológicos y ornamentales de las construcciones y, en general, a las condiciones de las obras de edificación que no sean definitorias de la edificabilidad o el destino del suelo, y asimismo, en términos compatibles con el planeamiento, las actividades susceptibles de autorización en cada inmueble. Todas las demás determinaciones urbanísticas solo las puede regular el planeamiento».

91 Baño León (2014: 18); Casado Echarren y Serrano Martín de Vidales (2021: 10).

92 En la línea propuesta por Velasco Caballero (2014: 8), de desplazamiento hacia estos sujetos del espacio funcional propio de la previa comprobación administrativa. En esta línea, DOMínGUEZ MARTín (2017: 119). A este respecto resulta muy sugerente la propuesta de IGLESIAS GONZÁLEZ (2015: 137), donde propugnaba no una "colaboración» de tales entidades privadas, sino que directamente las licencias fuesen otorgadas por tales entidades, reservándose los ayuntamientos la facultad de supervisión y control de la ejecución.

93 Casado Echarren y Serrano Martín de Vidales (2021: 10).

94 Baño León (2014: 16); Monteserín Heredia (2015: 124). 
el derecho a impugnar el resultado de la inspección ${ }^{95}$. La propuesta de un posible «acto municipal de toma de conocimiento» en todos los casos, o la existencia de un registro dotado de publicidad de todas las declaraciones o comunicaciones, como elemento susceptible de ser impugnado ${ }^{96}$ (a la vez que actúa como elemento de garantía del particular que formula la declaración o comunicación) resulta disfuncional respecto de ambas figuras, al convertirlas en realidad en una técnica de control previo encubierta.

\section{RÉGIMEN JURÍDICO}

\section{Concepto. ¿Ejercicio inmediato o diferido?}

La declaración responsable o la comunicación debe ser presentada por el operador o promotor, configurado como aquella persona física o jurídica titular de los derechos sobre el suelo y que promueve la obra de edificación o uso del suelo ${ }^{97}$. La declaración responsable se configura, art. 69.1 LPAC, como una declaración del interesado «bajo su responsabilidad» de que cumple con los requisitos establecidos en la normativa aplicable y de que dispone de la documentación que lo acredita, no resultando preciso, por tanto, que entregue previamente a la Administración tal documentación, si bien debe tenerla disponible para su exhibición caso de ser requerido en la fase posterior de control ${ }^{98}$. A su vez, la comunicación, art. 69.2 LPAC, identifica la comunicación como la puesta en conocimiento de la Administración pública competente de los datos identificativos del sujeto o cualquier otro dato relevante para el inicio de una actividad o el ejercicio de un derecho. La simplificación administrativa que se persigue con la figura de la declaración responsable, en su regulación básica contenida en el art. 69.1 LPAC, se plasma en la inexistencia de documentación complementaria a aportar, siendo una carga burocrática desproporcionada ${ }^{99}$. Desde esta perspectiva, la declaración responsable debería proyectarse a actividades que presenten cierta complejidad técnica y requieran un mayor conocimiento de la normativa exigida para el inicio de la actividad. A su vez, la comunicación debería circunscribirse a actuaciones «relativamente simples» ${ }^{100}$.

El art. 69 LPAC al regular el régimen general de la declaración responsable, en cuanto técnica de intervención administrativa adoptada por el Estado sobre la base del art. 149.1.18. ${ }^{\mathrm{a}}$, no determina los supuestos de hecho en los que el legislador autonómico puede recurrir a la misma. Ni siquiera a nivel principial. Se trata, de una norma referente

95 BAÑo LEÓN (2014: 19.

96 MONTESERÍN Heredia (2015: 125).

97 GONZÁlEz Bustos (2016: 20).

98 Muñoz Machado (2015: 235).

99 En esta línea, Rebollo Puig (2019a: 24). Resulta acertada la crítica de Domínguez Martín (2017: 114) sobre la «burocratización» de estas figuras, a semejanza de la licencia.

100 Zamorano Weis (2020: 21); García Gómez de Mercado (2020: 221); Domínguez Martín (2020: 2). 
al procedimiento administrativo común que establece los contenidos mínimos y el régimen común de tramitación ${ }^{101}$. Régimen jurídico que se impone a las Comunidades $\mathrm{Au}$ tónomas. Así, por ejemplo, no resulta necesario que la regulación normativa autonómica incorpore que la declaración responsable contenga la referencia "clara, expresa y precisa» a los requisitos establecidos en la normativa vigente para obtener el reconocimiento de un derecho o facultad, o para su ejercicio ${ }^{102}$. Al estar incorporada dicha exigencia por el art. 69 LPAC, la misma se configura como una norma del procedimiento común, por lo que la falta de una previsión similar en la normativa autonómica no libera al solicitante de la exigencia establecida en la normativa básica de que tales requisitos «deberán estar recogidos de manera expresa, clara y precisa» en la correspondiente declaración responsable. La competencia autonómica sectorial en materia urbanística lo que sí permite a las Comunidades es la concreción y adaptación, en su propia normativa autonómica o mediante su remisión a la regulación por ordenanza municipal, del contenido de esa declaración responsable o comunicación. Por ejemplo, puede exigirse, como concreción de la declaración del ajuste a la normativa vigente que «la actuación pretendida no se realiza sobre bienes que dispongan de algún tipo de protección de carácter ambiental o histórico-artístico, ya sea total o de elementos o partes objeto de protección, regulada a través de norma legal o documento urbanístico» [art. 156.1.c) Ley 9/2001, de Suelo de la Comunidad de Madrid ${ }^{103}$.

En ambos casos, la actuación del interesado incorpora, implícita o explícitamente, una manifestación sobre la adecuación a legalidad urbanística (así como a la legalidad sectorial exigible y controlable por el ayuntamiento: ruido, accesibilidad...) de la actuación comunicada o declarada sobre la base de su previa autoevaluación ${ }^{104}$. La legislación autonómica urbanística precisa la independencia de tales controles respecto de otros posibles controles previos exigidos por otras leyes sectoriales ${ }^{105}$. La simple presentación de la declaración incorpora la presunción iuris tantum de licitud del acto edificatorio o de uso del suelo ${ }^{106}$. Queda excluido así su carácter clandestino. El ordenamiento jurídico anuda a la formulación de la declaración o comunicación del interesado el surgimiento de una relación jurídico-administrativa (urbanística), en la que deben quedar garantizados los derechos del particular derivados del principio de buena administración.

La declaración responsable o la comunicación podrá ser presentada en soporte electrónico o en soporte papel, en función de la implantación efectiva de la Administración electrónica en el concreto ayuntamiento. Formulada la declaración responsable o la comunicación, el sujeto puede ejercer el derecho o iniciar desde el día de su presenta-

101 En este sentido, STC 70/2018, de 21 de junio, FJ 11.

102 No obstante, reiteran esta exigencia el art. 15 de la Ley 1/2021, de Aragón.

103 En la redacción dada por la Ley 1/2020.

104 Rebollo Puig (2019b: 47).

105 Crítico con la articulación actual, Rebollo PUig (2019b: 62).

106 Baño León (2018: 48). En contra, Rebollo Puig (2019b: 65), quien considera que «su situación es idéntica a la del que realiza una actividad ilegal sin haber hecho la declaración responsable o comunicación». 
ción ${ }^{107}$, todo ello sin perjuicio de las facultades de comprobación, control e inspección que tenga atribuida la Administración (este es el modelo que adoptan de Andalucía ${ }^{108}$, Aragón ${ }^{109}$, Castilla y León ${ }^{110}$, Extremadura ${ }^{111}$, Madrid ${ }^{112}$, Murcia ${ }^{113}$, o Navarra) ${ }^{114}$. El ejercicio del derecho por el ciudadano desde el momento de la presentación requiere que esta se efectúe en el registro de la Administración competente. ¿Qué ocurre cuando se presenta en el registro de otra Administración o a través de una oficina de correos? A priori podría parecer que hasta que no llegue al registro del órgano competente para comprobar tanto su corrección como su adecuación al objeto de esta técnica de control no podría iniciarse el ejercicio del derecho. No obstante, en la medida en que no se somete legalmente el ejercicio del derecho (el inicio de la actividad o de la facultad) a su comprobación, puede afirmarse la indiferencia del registro donde se presente, siempre que sea uno de los regulados en el art. 16.4 $\mathrm{LPAC}^{115}$.

No obstante esta regla general, algunas Comunidades Autónomas optan por un modelo que "pervierte» la funcionalidad de la declaración responsable o la comunicación, al exigir que la misma deba hacerse con un periodo de anticipación respecto del inicio de la actividad, con el fin de permitir a la Administración local verificar en ese primer momento inicial un "control preventivo» ${ }^{116}$. Con ello, de facto, se asimila la declaración responsable o la comunicación a una licencia. Este es el caso de Canarias ${ }^{117}$ o CastillaLa Mancha ${ }^{118}$. E incluso en algún supuesto, se somete a comunicación el inicio de las obras amparadas en una licencia (art. 154.3 Ley 9/2001, de Suelo de la Comunidad de Madrid) ${ }^{119}$ o en una declaración responsable [art. 169.bis.5.c) Ley 7/2002, de Ordenación Urbanística de Andalucía ${ }^{120}$; art. 157.2.b) Decreto Legislativo 1/2010, por el que se aprueba el Texto Refundido de la Ley de Ordenación del Territorio y de la Actividad Urbanística de Aragón] ${ }^{121}$, incorporando así la exigencia de un doble control previo,

107 Y ello incluso si existe un acto previo ejecutivo que ordena el cese de un uso o la paralización de obra edificatoria. Frente a lo defendido por Casado Echarren y Serrano Martín de Vidales (2021: 12), no puede aquí someterse la «eficacia» de la declaración responsable o la comunicación al acto de comprobación por el ayuntamiento. No existe dicha previsión normativa. Obviamente, si de la comprobación o inspección resulta la ilegalidad de la actuación, deberá dictarse una orden de cese.

108 Art. 169.3 Ley 7/2002, en la redacción dada por el Decreto-Ley 2/2020.

109 Art. 17 Ley $1 / 2021$.

110 Art. 105.quater Ley 5/1999, en la redacción dada por la Ley 7/2014.

111 Art. 164.1 Ley 11/2018.

112 Art. 157.1 Ley 9/2001, en la redacción dada por la Ley 1/2020.

113 Art. 266.2 Ley 13/2015.

114 Art. 195.7 Decreto Foral Legislativo 1/2017.

115 Gavieiro GonZÁlez (2020: 133).

116 Opción que es considerada como «posible y lógica» por Rebollo Puig (2019a: 26), si bien señala que no resulta oportuno seguir tal modelo.

117 Art. 350.1 Ley 4/2017.

118 Art. 158.2 Decreto Legislativo 1/2010, por el que se aprueba el texto refundido de la Ley de Ordenación del Territorio y de la Actividad Urbanística.

119 En la redacción dada por la Ley 1/2020.

120 En la redacción dada por el Decreto-Ley 2/2020.

121 En la redacción dada por la Ley 1/2021. 
lo que no se compadece bien con la pretendida simplificación administrativa y resulta contrario a la previsión básica del art. 69.6 LPAC $^{122}$.

Como opción normativa que permite el inicio inmediato de la actividad de ejecución sometida a comunicación urbanística, alguna Comunidad Autónoma (Galicia) reconoce esta posibilidad si la misma se acompaña de la certificación de conformidad a la legalidad urbanística y al planeamiento aplicable, emitida por una entidad de certificación de conformidad municipal (art. 54 Ley 9/2021 de Galicia), eliminando así el plazo legal de «antelación previa» establecido con carácter general ${ }^{123}$. En tal caso, se determina además que los informes técnicos y jurídicos municipales son simplemente facultativos y no preceptivos. ¿Resulta compatible dicha opción con la previsión del art. 9.2 del Real Decreto Legislativo 5/2015, de 30 de octubre, por el que se aprueba el Texto Refundido de la Ley del Estatuto Básico del Empleado Público ${ }^{124}$ ? La respuesta debe ser positiva ${ }^{125}$. Ciertamente, la certificación emitida por tales entidades se pronuncia sobre el ajuste técnico de lo propuesto al planeamiento aplicable, incorporando un informe sobre la validación del proyecto básico o de ejecución y la suficiencia e idoneidad de la documentación presentada y el resto de documentación (p. ej., art. 26 Ley 1/2021 Aragón). La misma tiene por finalidad agilizar el procedimiento de intervención, al existir un análisis técnico y jurídico, e imparcial, de carácter previo, que puede ser asumido por la Administración ${ }^{126}$. Tales entidades colaboradoras asumen o comparten la responsabilidad por los posibles daños o perjuicios que la actividad pueda deparar a terceros ${ }^{127}$. Pero en modo alguno sustituyen a la Administración en el ejercicio de sus funciones y competencias. De ahí que la entidad local pueda «en cualquier momento, verificar las funciones y actuaciones desarrolladas» por la entidad de certificación (art. 19.2 Aragón). Además, dicha certificación, que no excluye las facultades posteriores de control e inspección municipales ${ }^{128}$, en algún caso (Galicia) «limita» la posible responsabilidad por la

122 Cuestiona este modelo normativo Rebollo PUIG (2019a: 18), al resultar desproporcionado.

123 Que establece el art. 146.1 Ley 2/2016, de Suelo de Galicia, al requerir que «el promotor comunicará al ayuntamiento la intención de llevar a cabo el acto con una antelación mínima de quince días hábiles a la fecha en que pretenda comenzar su ejecución».

${ }_{124}$ Que dispone que «el ejercicio de las funciones que impliquen la participación directa o indirecta en el ejercicio de las potestades públicas o en la salvaguardia de los intereses generales del Estado y de las Administraciones Públicas corresponden exclusivamente a los funcionarios públicos, en los términos que en la ley de desarrollo de cada Administración Pública se establezca».

125 Pensado Seijas (2021: 1) cuestiona la eficacia de esta figura al afirmar que «La problemática subyacente es quién será el que asuma sin más esos informes».

126 La pregunta que surge cómo puede reaccionar el interesado frente una certificación "negativa». La única opción razonable es el recurso ante la Administración local.

127 Velasco Caballero (2014: 4), sin que ello prejuzgue el carácter administrativo o civil de la misma.

128 Y que en caso de ordenar el cese de la actividad no supone en todo caso la responsabilidad de la entidad colaboradora que certificó la adecuación de la declaración responsable. Como precisa la STSJ de Madrid de 25 de noviembre de 2020 (ECLI:ES:TSJM:2020:12914), la inversión finalmente llevada a cabo tiene su causa en las propias decisiones del particular, que es quién decide cuantas declaraciones responsables presenta, cuál es su contenido y «es, por tanto, la única responsable de las mismas. En definitiva, ella es la que se debe responsabilizar de la viabilidad del proyecto, libre y voluntariamente adoptado». 
comisión de una infracción urbanística a la propia entidad de certificación, excluyendo la del interesado que ha optado por su intervención como instrumento de verificación previa de la legalidad de la actuación propuesta.

\section{2. ¿Déficit de seguridad jurídica?}

La posible inseguridad jurídica para el sujeto privado $^{129}$ que formula la declaración responsable o la comunicación en algunos casos se intenta limitar por la legislación autonómica en dos momentos diferenciados. Con carácter previo a la formulación de la declaración responsable o comunicación mediante la posibilidad de formular una consulta previa al ayuntamiento sobre la viabilidad de la actuación urbanística proyectada (art. 157.3 Ley 9/2001, de Suelo de la Comunidad de Madrid ${ }^{130}$; o art. 195.5 Decreto Foral Legislativo 1/2017, de Ordenación del Territorio y Urbanismo de Navarra). En otros ocasiones, a través de la posible obtención de un certificado emitido por una entidad colaboradora de certificación urbanística ${ }^{131}$ que acompañe a la declaración responsable (art. 54 Ley 9/2021, de simplificación administrativa y de apoyo a la reactivación económica de Galicia). En un segundo momento, se intenta dotar de seguridad jurídica al sujeto que ha formulado la declaración responsable o la comunicación mediante la obligación municipal de emitir un certificado de la presentación de la declaración responsable y su compatibilidad con la ordenación aplicable (Aragón ${ }^{132}$ y Extremadura ${ }^{133}$ ). En algún caso ese intento de dotar de seguridad al interesado se articula posibilitando que solicite, de forma voluntaria, una licencia para una actividad que inicialmente no está sometida a la misma (Canarias ${ }^{134}$ y Murcia ${ }^{135}$ ). Esta opción debe ser criticada por no respetar el principio de proporcionalidad ${ }^{136}$. Resulta menos restrictiva la figura del certificado emitido por el ayuntamiento.

Formulada la declaración responsable o la comunicación, el acto edificatorio o de uso del suelo se proyecta con carácter real sobre la parcela a la que está vinculada, por lo que si se produce una transmisión del terreno, el nuevo adquirente podrá ejecutarlo o continuar con su implantación ${ }^{137}$.

129 Sobre ello, Rebollo Puig (2019a: 21); García Gómez de Mercado (2020: 234).

130 En la redacción dada por la Ley 1/2020.

131 Y aquí el riesgo que surge es que, ante la falta de densidad normativa derivada de la relación entre la Ley autonómica y la ordenación establecida en el plan o la correspondiente ordenanza, dichas entidades de certificación «se conviertan en instancias auxiliares de regulación, supliendo esa menor densidad a través de un ejercicio de discrecionalidad que no les corresponde», como denunció NúŃEZ LOZANO (2015: 5).

132 Art. 18.4 Ley 1/2021 de Aragón.

133 Art. 166.2 Ley 11/2018.

134 Art. 332.3 Ley 4/2017.

135 Art. 263.3 Ley 13/2015.

136 Se muestra dubitativo Rebollo Puig (2019a: 21).

137 García Gómez de Mercado (2020: 231). 


\section{Comprobación e inspección}

La presentación de la comunicación o la declaración responsable sitúa al interesado bajo las facultades de comprobación e inspección del ayuntamiento ${ }^{138}$. Y lo hace porque a tal actuación del interesado el ordenamiento jurídico anuda la existencia de una relación jurídico-administrativa. La clave de bóveda del sistema reside en la concreción de los procedimientos, contenidos y garantías, frente a los actos posteriores de verificación, control e inspección, art. 69.3 LPAC, si bien la legislación básica estatal aquí solo enuncia tales facultades atribuidas a la Administración ${ }^{139}$, correspondiente su regulación al ámbito autonómico ${ }^{140}$. Por tanto, el elemento central es la regulación de la verificación del control ex post en tiempo y forma ${ }^{141}$. El principio de buena administración y su concreción en el principio de seguridad jurídica requiere acotar esa facultad de control a un control estricto de legalidad (nunca de oportunidad), lo que requiere que la norma establezca con claridad el supuesto de hecho, evitando posibles situaciones ambiguas ${ }^{142}$. Es más, ese control se circunscribe a la legalidad urbanística y a la legalidad sectorial que anude su comprobación al control municipal de las actuaciones edificatorias o de uso del suelo ${ }^{143}$. Ante la falta de regulación básica legal expresa, tales procedimientos de comprobación e inspección deben garantizar la necesaria contradicción y la graduación de las consecuencias de un posible incumplimiento. Y aquí resulta totalmente correcta la crítica efectuada a las diversas leyes autonómicas, ante la inexistencia de una regulación acabada y coherente que adecue las potestades de disciplina urbanística a las figuras de la declaración responsable y la comunicación previa ${ }^{144}$.

\section{Comprobación. La sustitución de la comprobación municipal por la actuación de una entidad externa colaboradora}

¿Cuál es el alcance de la comprobación que debe realizar la Administración local? En otros términos, ¿qué es lo que debe comprobarse? En el momento de la presentación, el ayuntamiento realiza un control de alcance limitado, centrándose en los aspectos formales. Comprueba que la documentación presentada es completa y que la actividad descrita por el sujeto no requiere la obtención de una licencia, y que la misma es, prima facie, ajustada al ordenamiento urbanístico aplicable a la parcela ${ }^{145}$. Por tanto, la facultad

138 BAÑO LEÓN (2018: 49).

139 Lo que es criticado por MuÑoz Machado (2015: 236), y Domínguez Martín (2017: 112).

140 Gifreu Font (2014: 202).

141 Ibid.: 185.

142 No parece un enfoque metodológico correcto apreciar que la declaración responsable solo puede operar ante facultades regladas de la Administración.

143 Rebollo Puig (2019b: 48).

144 Rebollo Puig (2019a: 16).

145 Rebollo Puig (2019b: 23). 
administrativa de comprobación (formal) se proyectará sobre la veracidad de los datos y de los documentos aportados, así como el cumplimiento de los requisitos formales exigi$\operatorname{dos}^{146}$. Se trata de una actuación de obligado ejercicio, que requerirá el análisis, sobre la base de los informes técnicos y jurídicos, acerca de si la documentación presentada está completa y es correcta ${ }^{147}$. Si la documentación es incompleta o incurre en algún error no esencial, deberá necesariamente requerirse al interesado que la complete ${ }^{148}$, no pudiendo continuarse con el ejercicio del derecho o actividad afectada hasta la subsanación, art. 69.4 LPAC. El requerimiento de subsanación no puede ser configurado como un simple acto de trámite, en la medida en que, bien de forma expresa bien implícitamente, impide continuar con el ejercicio del derecho mientras no se cumplimente, por lo que puede ser objeto de los correspondientes recursos en vía administrativa y contenciosoadministrativa ${ }^{149}$. Si la subsanación efectuada por el particular resulta inadecuada (o no se produce), la Administración local podrá acordar el cese de los efectos de la declaración responsable o la comunicación ${ }^{150}$.

En un segundo momento, debe verificarse un control material sobre la adecuación de la actuación edificatoria o de uso del suelo a la normativa aplicable a la parcela. Si la Administración advierte que la actividad o uso que se pretende realizar no constituye uno de los supuestos sometidos a declaración responsable o resulta contraria a la ordenación territorial y urbanística aplicable sobre la parcela podrá ejercer un derecho de veto, dictando una resolución administrativa expresa que niegue la posibilidad de realizar la actuación y ordene el cese de la misma. Esto es, acordará la suspensión administrativa del acto edificatorio o de uso del suelo y el ejercicio de las facultades de restablecimiento de la legalidad urbanística infringida y sancionadora en materia urbanística. La misma actuación administrativa deberá realizarse si se aprecia la concurrencia de un error esencial, donde no resultará procedente requerir la subsanación ${ }^{151}$, si bien parece razonable otorgar en ambos casos un trámite de audiencia al particular ${ }^{152}$. Aquí se ejerce un control (reglado) sobre la legalidad urbanística, con la extensión fijada por la legislación autonómica ${ }^{153}$. Así, por ejemplo, la resolución municipal que determine la pérdida de la eficacia de la declaración responsable puede, igualmente, determinar la obligación

146 Art. 159.3 Ley 9/2001, de Suelo de la Comunidad de Madrid, en la redacción dada por la Ley 1/2020.

147 GAVIEIRO GonZÁLEZ (2020: 135). Ahora bien, aquí no hay un procedimiento administrativo iniciado sobre la base de la solicitud del interesado, como precisa Rebollo Puig (2019b: 23). Pero sí existe un procedimiento administrativo, interno, inicialmente sin eficacia externa, de verificación y control.

148 No resulta proporcionado declarar directamente el cese de la actividad, como parecen sugerir CASADO ECharREN y SERRANo MarTín de Vidales (2021: 9). El principio de buena administración lo impide. En este sentido, p. ej., STSJ de Madrid de 22 de septiembre de 2020 (ECLI:ES:TSJM:2020:10677).

149 Gavieiro GonZÁlez (2020: 136); Rebollo Puig (2019b: 24).

150 GaVieiro GonZÁlez (2020: 140).

151 STSJ de Madrid de 30 de noviembre de 2020 (ECLI:ES:TSJM:2020:13797), que considera como tal el que las obras proyectadas supongan un cambio de actividad no permitido.

152 GaVieIro GonZÁlez (2020: 141). No obstante, ello es negado de forma reiterada por el TSJ de Madrid. P. ej., en la STSJ de Madrid de 12 de noviembre de 2020 (ECLI:ES:TSJM:2020:12975), al considerar que ello supondría permitir el uso o la actividad edificatoria en tanto se resuelve.

153 García Gómez de Mercado (2020: 228). 
de restituir la situación jurídica al momento previo del inicio de los actos de transformación, construcción, edificación y uso del suelo, el subsuelo y el vuelo (arts. 157.7 y 159.4 Ley 9/2001, de Suelo de la Comunidad de Madrid). Pero ello solo será posible si no resulta viable la legalización de la actividad realizada o en curso de realización. La orden de cese de la actividad es susceptible de recurso en vía contencioso-administrativa, donde la postura jurisprudencial es negar la medida cautelar de suspensión de tal acto al ser un acto de contenido negativo ${ }^{154}$.

Ese control material debe efectuarse en un plazo limitado [art. 169.bis.4 Ley 7/2002, de Ordenación Urbanística de Andalucía ${ }^{155}$; art. 158.5.a) Decreto Legislativo 1/2010, por el que se aprueba el Texto Refundido de la Ley de Ordenación del Territorio y de la Actividad Urbanística de Aragón ${ }^{156}$; art. 350.2 Ley 4/2017, de Suelo y Espacios Naturales de Canarias; art. 164.7 Ley 11/2018, de Ordenación Territorial y Urbanística Sostenible de Extremadura; art. 159.4 Ley 9/2001, de Suelo de la Comunidad de Madrid ${ }^{157}$; art. 146.2 Ley 2/2016, del suelo de Galicia]. Obviamente, el simple transcurso de ese plazo no «legaliza» la actuación realizada en su caso, ni su incumplimiento se configura como esencial.

¿Existe o debe existir un plazo máximo para verificar ese control ex post por parte de la Administración local? Se ha afirmado la inexistencia de plazo alguno para ejercer la facultad de comprobación ${ }^{158}$, rechazándose la operatividad del principio de confianza legítima ante la inexistencia de acto administrativo alguno generador de la misma ${ }^{159}$. Pero razones de seguridad jurídica y eficiencia administrativa permiten concluir en la necesidad de establecer dicho plazo, donde una Administración dotada de una adecuada organización administrativa podría verificar dicha comprobación. En el caso de Aragón, el plazo se fija en seis meses (susceptible de ser reducido por una norma legal o reglamentaria). Si transcurre dicho plazo, el interesado podrá "provocar» la emisión por el órgano o entidad competente de un acto de conformidad, de carácter reglado al con-

154 P. ej., STSJ de Madrid 18 de noviembre de 2020 (ECLI:ES:TSJM:2020:12830), donde se afirma que «en los supuestos en el que el ejercicio de la actividad o la realización de una obra se somete al sistema de declaración previa ( declaración responsable) si la misma es declarada ineficaz la consecuencia jurídica directa es la imposibilidad de continuar con el ejercicio del derecho o actividad afectada desde el momento en que se tenga constancia de tales hechos, de forma que declarada la ineficacia de la declaración responsables la misma supone su pérdida de validez aunque cuente con el certificado de conformidad de una entidad colaboradora. Ello supone la inexistencia de título que habilite para el ejercicio de lo pretendido en la declaración responsable y la declaración de ineficacia no es susceptible de suspensión pues en el nuevo sistema de intervención administrativa en las actividades la declaración responsable deja de producir efectos si se declara su ineficacia, y la suspensión de esta resolución administrativa tendría los mismos efectos que la denegación de una licencia es un acto de contenido negativo, los cuales no admiten suspensión pues en este caso se estaría adelantando el fallo estimatorio del recurso".

155 En la redacción dada por el Decreto-Ley 2/2020.

156 En la redacción dada por la Ley $1 / 2021$.

157 En la redacción dada por la Ley $1 / 2020$.

158 Rebollo Puig (2019b: 23).

159 BAÑo LEÓN (2018: 50) argumenta que la renuncia de la Administración al procedimiento administrativo sitúa al interesado en una situación de «revocación permanente de su situación». 
figurarse como un derecho del interesado ${ }^{160}$. Extremadura ${ }^{161}$ no fija plazo alguno, pero incorpora igualmente la emisión de un acto de comprobación («documento de toma de conocimiento») tras la comprobación municipal. Madrid ${ }^{162}$ fija el plazo en tres meses, incorporando en caso de comprobarse la adecuación, un acto de conformidad.

\section{5. ¿Caducidad de la eficacia de la declaración responsable?}

Solo alguna norma autonómica regula el plazo de vigencia de la declaración responsable o comunicación, al determinar que la misma perderá su eficacia si los actos edificatorios o de uso del suelo que legitiman no se inician en un periodo determinado. Así, por ejemplo, la legislación extremeña ${ }^{163}$ determina la caducidad, previa tramitación del procedimiento administrativo correspondiente con audiencia del interesado, si las obras o usos se hayan iniciado en el plazo de seis meses. Nada señala respecto a su finalización. A su vez, la legislación madrileña ${ }^{164}$, con una regulación más acabada, exige que las actuaciones amparadas en una declaración responsable urbanística se inicien en un plazo máximo de seis meses y se finalicen en un plazo máximo de un año desde su presentación, sin perjuicio de la posibilidad de conceder una sola prórroga por idénticos plazos. En tales supuestos, la declaración de caducidad requiere la tramitación del correspondiente procedimiento donde se otorgue audiencia al interesado que formuló la declaración responsable (o al sujeto al que se haya transmitido la parcela y, con ella, la eficacia de la declaración responsable). Es razonable aplicar analógicamente la doctrina jurisprudencial sobre la caducidad de las licencias, de tal forma que en tanto no se incoe el procedimiento de declaración de caducidad (y aún iniciado este, si no se aprecia una voluntad clara de no iniciar, ejecutar o culminar la obra), estas podrán continuar.

¿Qué ocurre en el resto de Comunidades Autónomas que no regulan expresamente esta figura? La falta de previsión legal avoca a considerar que no existe plazo alguno para iniciar y culminar las obras o actos de uso del suelo a los que otorga cobertura la declaración responsable o la comunicación previa, aunque cuando ello resulte disfuncional ${ }^{165}$. No cabe aplicar analógicamente la regulación (plazos de iniciación, ejecución y finalización) fijados para las licencias.

\section{Inspección. ¿Revisión o revocación de las declaraciones responsables?}

A través de las facultades de inspección la Administración procede a constatar si el ejercicio de la concreta actividad se corresponde o no con la descripción realizada en

160 Art. 18.4 Ley 1/2021 de Aragón.

161 Art. 166.2 Ley 11/2018.

162 Art. 159, apartados 4 y 5, Ley 9/2001, en la redacción dada por la Ley 1/2020.

163 Art. 165 Ley $11 / 2018$.

164 Art. 158 Ley 9/2001, en la redacción dada por la Ley 1/2020.

165 Rebollo Puig (2019: 27). 
la comunicación, procediendo en caso contrario a la imposición de la correspondiente sanción o incluso a revocar la licencia que a través de la comunicación se entienda otorgada. Se efectúa así una actividad de constatación con respecto al cumplimiento de una norma, comprobando ante la sospecha o simplemente de modo sistemático, el grado de adecuación de la actividad real ejecutada a las prescripciones de la normativa urbanísti$\mathrm{ca}^{166}$. Dada la complejidad de la actuación a controlar, se requiere que la inspección esté dotada de los necesarios medios personales, y que estos cuenten con la debida especialización técnica ${ }^{167}$.

Nuevamente aquí surge la pregunta de la existencia de un plazo máximo o el carácter temporalmente ilimitado de la facultad de inspección. Frente a la postura que defiende la inexistencia de límite temporal alguno ${ }^{168}$, debe mantenerse que la relación jurídicoadministrativa de carácter urbanístico trabada está sometida a las mismas reglas de prescripción que en el caso de las actuaciones con licencia. Por ello, transcurrido el plazo fijado en la legislación autonómica desde la finalización de su ejecución o implantación, decaerán la facultad de inspección y de restablecimiento de la legalidad urbanística, si esta ha sido infringida ${ }^{169}$.

Verificada una actuación inspectora, si la actuación incorporada en la declaración responsable (o en la comunicación) que ha sido efectivamente implantada o ejecutada se ajusta a la normativa de aplicación sobre la parcela, el ayuntamiento no deberá adoptar ningún tipo de acto jurídico para «complementar» o "validar» la actuación del ciudadano. Solo si no se ajusta a lo declarado o lo ejecutado no se ajusta a la normativa, la actuación inspectora, que debe plasmarse en la correspondiente acta, concluirá en una resolución municipal que determinará la "pérdida de efecto» inmediato de la declaración responsable o de la comunicación, acordando la paralización de las obras o el cese de la actividad o de la actuación realizada, así como la obligación de la persona interesada de restituir la situación jurídica al momento previo al reconocimiento o al ejercicio del derecho o al inicio de la actividad correspondiente, si las deficiencias detectadas constituyen inexactitud, falsedad u omisión de carácter esencial conforme al art. 69 LPAC, lo que determina la imposibilidad de continuar en el ejercicio del derecho y, en su caso, a la incoación del correspondiente procedimiento sancionador. La resolución administrativa determina el cese de la eficacia de la declaración responsable, resurgiendo de nuevo la prohibición general.

No se trata de un supuesto de nulidad o anulabilidad de la declaración responsable o comunicación ${ }^{170}$, como alguna norma autonómica incorrectamente determina (expresamente art. 195.7 Decreto Foral Legislativo 1/2017, de Ordenación del Territorio y Urbanismo de Navarra, e indirectamente al aludir a la validez, art. 164.10 Ley 11/2018,

166 DOMÍNGUEZ MARTín (2020: 1).

167 GAVIEIRO GONZÁlEZ (2020: 137).

168 Rebollo Puig (2019b: 24).

169 Gavieiro GonZÁlez (2020: 142).

170 Crítico con esa construcción, Rebollo PUIG (2019b: 26). 
de Ordenación Territorial y Urbanística Sostenible de Extremadura). No se afecta al plano de validez de una decisión administrativa, sino al plano de la eficacia de una actuación del interesado.

Aquí la Administración local, para adoptar esa concreta resolución que determine la ineficacia de la declaración responsable, debe tramitar el correspondiente procedimiento administrativo. ¿Debe requerirse en dicho procedimiento que el interesado presente la documentación que falte o que posibilite considerar correcta la comunicación o declaración responsable presentada, y concediendo un plazo para verificar la «subsanación»? La respuesta afirmativa se propugna por la doctrina ${ }^{171}$ y la jurisprudencia cuando la inexactitud, falsedad u omisión puedan calificarse de no esenciales. Por el contrario, si tales defectos son sustanciales, el procedimiento requiere incorporar un trámite de audiencia al interesado, pero no un trámite de subsanación ${ }^{172}$. El problema normativo se traslada a determinar qué requisitos son esenciales y cuáles no.

En la medida en que la declaración responsable no incorpora ningún acto administrativo, no siendo un título habilitante, no pueden utilizarse las técnicas de eliminación de los actos administrativos. Las mismas no se proyectan sobre ninguna decisión de la administración, sino sobre la actuación del ciudadano. Por ello resultan conceptualmente incorrectas las referencias normativas (art. 161 Ley 9/2001, de Suelo de la Comunidad de Madrid ${ }^{173}$; art. 155.2 Ley 12/2017, de Urbanismo de las Islas Baleares) y jurisprudenciales ${ }^{174}$ a la revisión o a la revocación de la declaración responsable ${ }^{175}$. En efecto, tanto Baleares como Madrid permiten que ante una alteración del planeamiento urbanístico se «revoque» la declaración responsable. Así, en Baleares, cuando «no se haya superado el plazo para el inicio o la finalización de las obras, la administración podrá iniciar, si así lo recomienda el interés público, el expediente de revocación o modificación del título habilitante, previa audiencia a las personas interesadas, asumiendo la indemnización oportuna». En Madrid, de estar ya iniciado el acto de ejecución, el ayuntamiento «podrá revocar el título habilitante, o permitir la terminación de las obras, quedando el edificio en situación de fuera de ordenación", o si se ha iniciado el acto de ejecución, «procederá a la revocación del título habilitante», igualmente con audiencia del interesado y de acordarse la revocación, se establecerá en la misma resolución la indemnización que, en su caso, corresponda.

Ahora bien, que resulte metodológicamente incorrecta la referencia a la técnica de la revocación como mecanismo de eliminación de actos administrativos no impide que la legislación autonómica sí pueda determinar, como mecanismo no solo frente al incumplimiento de lo declarado o comunicado, sino también cuando ello resulte con-

171 GaVieiro GonZÁLEZ (2020: 139).

172 GavieIro GonZÁlez (2020: 141).

173 En la redacción dada por la Ley 1/2020.

174 P. ej., la STSJ de Madrid de 6/2/2020, que afirma que tal decisión administrativa implica «revocar la licencia que a través de la comunicación se entienda otorgada». El dislate metodológico es manifiesto.

175 Rebollo Puig (2019b: 26). 
trario a la legalidad existente en el momento de efectuar la declaración o comunicación o en un momento posterior antes de la culminación de la actuación edificatoria o de uso del suelo, la cesación del reconocimiento de efectos jurídico-públicos a la actuación del particular $^{176}$. Y ello se producirá mediante la orden municipal de cese ${ }^{177}$. En este último supuesto, debe reconocerse la posibilidad de que pueda producirse un supuesto de responsabilidad patrimonial de la Administración, pero solo si el instrumento de planeamiento inicialmente vigente permitía la edificación o uso urbanístico declarado o comunicado ${ }^{178}$.

\section{Restablecimiento de la legalidad infringida y responsabilidad por la comisión de infracciones urbanísticas}

La mayoría de las leyes autonómicas optan por una remisión en bloque al sistema de restablecimiento de la legalidad urbanística infringida y al sistema sancionador en materia de urbanismo, bien mediante la equiparación a las actuaciones sin licencia de aquellos supuestos donde las actuaciones sujetas a declaración responsable se realicen sin haberse presentado la misma, cuando sea preceptiva, o que excedan de las declaradas, considerándose obras y usos clandestinos (art. 169.bis.6. Ley 7/2002, de Ordenación Urbanística de Andalucía ${ }^{179}$; art. 159.1 Decreto Legislativo 1/2010, por el que se aprueba el Texto Refundido de la Ley de Ordenación del Territorio y de la Actividad Urbanística ${ }^{180}$; art. 195.6 Decreto Foral Legislativo 1/2017, de Ordenación del Territorio y Urbanismo de Navarra), bien mediante la articulación de dicho sistema sobre la base general de la realización de actos de uso del suelo sin el correspondiente título habilitante, licencia o declaración responsable/comunicación (art. 350.3 Ley 4/2017, de Suelo y Espacios Naturales de Canarias; arts. 152 y 153 Ley 2/2016, del suelo de Galicia; art. 157.6 Ley 9/2001, de Suelo de la Comunidad de Madrid) ${ }^{181}$.

¿Cómo se lleva a cabo el restablecimiento de la legalidad infringida cuando la actuación carece de declaración responsable o comunicación, o no se ajusta a lo incorporado a las mismas y dicha actuación es legalizable? Solo en el caso de Canarias se establece expresamente que ahí el procedimiento de legalización deberá instrumentarse a través de la solicitud de una licencia municipal ${ }^{182}$, salvo «que la legalización se opere antes de la notificación de la incoación del expediente de restablecimiento de la legalidad urbanística o que afecte a actuaciones de escasa relevancia o cuantía así

\footnotetext{
176 Muñoz Machado (2015: 237).

177 Rebollo Puig (2019b: 26).

178 Ibid.: 70.

179 En la redacción dada por el Decreto-Ley 2/2020.

180 En la redacción dada por la Ley $1 / 2021$.

181 En la redacción dada por la Ley 1/2020.

182 Art. 332.4 Ley 4/2017.
} 
determinadas en la respectiva ordenanza local». Esta regulación se presenta desenfocada. Si la ilegalidad consiste en haber ejecutado una actuación que, normativamente, requería la previa obtención de licencia, el restablecimiento se ajustará a las previsiones correspondientes de la ley autonómica para las actuaciones sin licencia ${ }^{183}$. Si la ilegalidad consiste en no haber formulado con carácter previo la declaración responsable o la comunicación, o bien en no haberse ajustado estrictamente a la misma (siendo lo materializado ajustado a la legalidad urbanística aplicable), el restablecimiento deberá efectuarse mediante la correspondiente formulación de la declaración responsable o comunicación ajustada al contenido del acto edificatorio o de uso del suelo ejecutado o en curso de ejecución. Pero aquí tal declaración responsable o comunicación se formula como consecuencia de un procedimiento administrativo previo de restablecimiento de la legalidad urbanística, con audiencia al interesado, que concluirá con el requerimiento para formular tal declaración o comunicación. Si la actuación no resulta legalizable, o no se formula la declaración o comunicación requerida, el ayuntamiento deberá ordenar la demolición de lo construido ilegalmente y el restablecimiento de la realidad física alterada ${ }^{184}$.

La inactividad de la Administración en orden a restablecer la legalidad infringida determina la atribución legal de la responsabilidad objetiva a la propia Administración local si esta no adopta las medidas necesarias para el cese del acto o uso en el plazo de seis meses, por los perjuicios que puedan ocasionarse a terceros de buena fe por la omisión de tales medidas responsable [art. 169.bis.4.d) Ley 7/2002, de Ordenación Urbanística de Andalucía ${ }^{185}$; art. 159.2.d) Decreto Legislativo 1/2010, por el que se aprueba el Texto Refundido de la Ley de Ordenación del Territorio y de la Actividad Urbanística de Castilla-La Mancha ${ }^{186}$, y art. 157.2 Ley 9/2001, de Suelo de la Comunidad de Madrid] ${ }^{187}$. Estas Comunidades Autónomas asumen y extienden la aplicación de la regulación prevista por el art. 11.5 TRLSRU para las declaraciones responsables que tengan por objeto el control de la primera ocupación o utilización de las edificaciones cuando las mismas no cumplen los requisitos necesarios para el destino al uso previsto, y la entidad local no adopta las medidas necesarias para el cese de la ocupación o utilización comunicada.

Obviamente, la formalización de una declaración responsable no podrá ser invocada para excluir o disminuir la responsabilidad civil o penal en que pueda incurrir su promotor en el ejercicio de los actos a los que se refiera.

183 Rebollo Puig (2019b: 28); Chinchilla Peinado (2008: 69).

184 Así, STSJ de Castilla y León (Sala de Burgos) de 7 de junio de 2019 (ECLI:ES:TSJCL:2019:2577), donde precisa que «no procede resolver si lo ejecutado es conforme a la declaración responsable formulada, sino si lo ejecutado es conforme con la legislación urbanística».

185 En la redacción dada por el Decreto-Ley 2/2020.

186 En la redacción dada por la Ley 1/2021.

187 En la redacción dada por la Ley $1 / 2020$. 


\section{Anulación judicial del plan y declaraciones responsables y comunicaciones previas}

Se ha planteado que ante la anulación judicial del instrumento de planeamiento, la previsión del art. 73 LJCA no resulta aplicable a las declaraciones responsables o a las comunicaciones, dado que no existe un acto autorizatorio firme, por lo que el ayuntamiento podría ordenar en cualquier momento la reposición de la realidad alterada si el acto edificatorio o de uso de suelo realizado resulta disconforme con el plan revivido y que deviene aplicable ${ }^{188}$. No parece asumible esta solución. Ciertamente no existe un acto administrativo firme, pero sí existe una relación jurídico-administrativa surgida de la actuación del interesado y a la que el ordenamiento jurídico reconoce efectos. Desde esta perspectiva, el principio de buena administración y el principio de confianza legítima, derivado bien del efectivo ejercicio de la facultad de comprobación realizada por el ayuntamiento bien de la falta de tal comprobación en el plazo estipulado, debe conducir a considerar incorporado al patrimonio del interesado el acto edificatorio o del uso del suelo ejecutado al amparo de la declaración responsable o de la comunicación y, por tanto y si no ha sido cuestionado en sede jurisdiccional, inmune a las facultades de inspección y restablecimiento de la legalidad urbanística sobre la base del planeamiento «revivido».

\section{BIBLIOGRAFÍA}

BAÑO LEÓN, J. M.a: «Declaración responsable y derechos de terceros. El lado oscuro de la llamada "better regulation"”, Revista Española de Derecho Administrativo, núm. 167, 2014, pp. 23-44.

- «Derecho al procedimiento en la relación administrativa multipolar (los derechos fundamentales como límite a la renuncia del legislador al control previo de actuaciones)», Revista Española de Derecho Administrativo, núm. 189, 2018, pp. 47-67.

Casado Echarren, A., y MarTín De Vidales, C. S.: «La autoejecución del planeamiento urbanístico a través de la declaración responsable. Problemas prácticos», Práctica Urbanística, núm. 168,(2021, pp. 1-22.

Chinchilla Peinado, J. A.: «El control municipal de los actos de uso del suelo y edificación a través de la figura de la comunicación previa como alternativa a la licencia urbanística. Análisis de la regulación legal y municipal y de la aplicación judicial», Revista de Derecho Administrativo y Medio Ambiente, núm. 242, 2008, pp. 13-86.

DoméneCh PASCUAL, G.: «¿iMejor antes o después? Controles públicos previos versus controles públicos posteriores», Papeles de economía española, núm. 151, 2017, pp. 47-62.

DOMíngueZ MARTín, M.: «La transformación del control local: de la licencia urbanística a la actuación comunicada», Revista de Derecho Urbanistico y Medio Ambiente, núm. 311, 2017, pp. 101-124.

188 Como propone Rebollo PUig (2019b: 72), que considera inaplicable tal regulación, al no existir un acto administrativo firme. 
— «Los mecanismos de limitación-intervención en el ámbito urbanístico: licencias, comunicaciones y declaraciones responsables en la STC 143/2017, de 14 de diciembre», Práctica Urbanistica, núm. 164, 2020, pp. 1-13.

GaVIEIRO GONZÁLEZ, S.: «Declaraciones responsables y comunicaciones: efectos y tramitación. Especial referencia al ámbito urbanístico. Análisis jurisprudencial», Revista Vasca de Administración Pública, núm. 118, 2020, pp. 127-152.

GarCía GÓmeZ De MerCado, F.: «Declaración responsable o comunicación previa como sustitutivas de las licencias urbanísticas», Revista de Derecho Urbanistico y Medio Ambiente, núms. 337-338, 2020, pp. 201-247.

GIFREU FONT, J.: «La impronta de la Directiva de servicios y de la normativa de transposición interna estatal en las técnicas interventoras urbanísticas. Parada y fonda: la Ley de garantía de la unidad de mercado", Revista Vasca de Administración Pública, núm. 98, 2014, pp. 169-213.

GonZÁlez Bustos, M. ${ }^{a}$ de los Á.: «Simplificación administrativa, licencias urbanísticas y declaración responsable», Revista Jurídica de Castilla y León, núm. 39, 2016, pp. 1-30.

IgLESIAS GonZÁlez, F.: «Siete medidas urgentes para salvar el urbanismo», Revista de Derecho Urbanistico y Medio Ambiente, núm. 301, 2015, pp. 77-150.

MONTESERÍN HEREDIA, S.: «Crónica del desembarco y conquista del régimen de intervención de la Directiva de Servicios en el derecho urbanístico español», Cuadernos de Derecho Local, núm. 38, 2015, pp. 116-149.

Muñoz Machado, S.: «Tratado de Derecho Administrativo y Derecho Público General», La actividad regulatoria de la Administración, t. XIV, 2015.

NúŃEZ LoZANO, M. a del C.: "Las declaraciones responsables y las comunicaciones en el proyecto de Ley del Procedimiento Administrativo Común de las Administraciones Públicas», Documentación Administrativa, núm. 2, 2015.

Pensado Seijas, A.: «Comentarios a la Ley 9/2021, de 25 de febrero, de simplificación administrativa y de apoyo a la reactivación económica de Galicia: ¿Liberalización de funciones públicas?», El Consultor de los Ayuntamientos (febrero de 2021).

Rebollo Puig, M.: «De las licencias urbanísticas a las declaraciones responsables», Revista de Estudios de la Administración Local y Autonómica, núm. 1, 2019a, pp. 6-28.

- «Disciplina urbanística y declaraciones responsables», Revista Española de Derecho Administrativo, núm. 198, 2019b, pp. 45-92.

Santamaría Pastor, J. A.: «Los proyectos de Ley del Procedimiento Administrativo Común de las Administraciones Públicas y de Régimen Jurídico del Sector Público: una primera evaluación», Documentación Administrativa, núm. 2, 2015, pp. 1-15.

Velasco Caballero, F.: «Sujetos privados en las comunicaciones previas y las declaraciones responsables para el control municipal de actividades económicas", Revista Española de Derecho Administrativo, núm. 165, 2014, pp. 1-45.

Velasco Caballero, F.: Derecho Urbanistico de la Comunidad de Madrid, 2. ${ }^{a}$ ed., 2021.

Zamorano WeIs, J.: «El Decreto-Ley 2/2020 del gobierno andaluz. Hacia la privatización de la potestad de ordenación del territorio. Las declaraciones responsables en materia urbanística. La intervención de los particulares en elementos del entorno de bienes del patrimonio cultural o histórico", Revista General de Derecho Administrativo, núm. 55, 2020, pp. 1-41. 